\title{
Article \\ Efficient Chitosan/Nitrogen-Doped Reduced Graphene Oxide Composite Membranes for Direct Alkaline Ethanol Fuel Cells
}

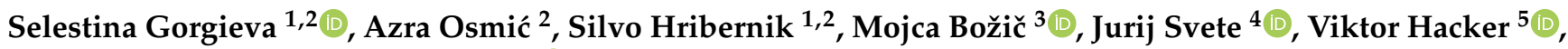 \\ Sigrid Wolf ${ }^{5}$ and Boštjan Genorio ${ }^{4, *(1)}$
}

1 Faculty of Mechanical Engineering, University of Maribor, Smetanova 17, 2000 Maribor, Slovenia; selestina.gorgieva@um.si (S.G.); silvo.hribernik@um.si (S.H.)

2 Faculty of Electrical Engineering and Computer Science, University of Maribor, Koroška cesta 46, 2000 Maribor, Slovenia; azra.osmic@um.si

3 Dravske Elektrarne Maribor d.o.o., Obrežna ulica 170, 2000 Maribor, Slovenia; mojca.bozic@dem.si

4 Faculty of Chemistry and Chemical Technology, University of Ljubljana, Večna pot 113, 1000 Ljubljana, Slovenia; jurij.svete@fkkt.uni-lj.si

5 Institute of Chemical Engineering and Environmental Technology, Graz University of Technology, Stremayrgasse 9, 8010 Graz, Austria; viktor.hacker@tugraz.at (V.H.); sigrid.wolf@tugraz.at (S.W.)

* Correspondence: bostjan.genorio@fkkt.uni-lj.si; Tel.: +386-1-479-8586

Citation: Gorgieva, S.; Osmić, A.; Hribernik, S.; Božič, M.; Svete, J.;

Hacker, V.; Wolf, S.; Genorio, B.

Efficient Chitosan/Nitrogen-Doped Reduced Graphene Oxide Composite Membranes for Direct Alkaline Ethanol Fuel Cells. Int. J. Mol. Sci. 2021, 22, 1740. https://doi.org/ $10.3390 /$ ijms 22041740

Academic Editor: Iolanda Francolini Received: 27 January 2021

Accepted: 3 February 2021

Published: 9 February 2021

Publisher's Note: MDPI stays neutral with regard to jurisdictional claims in published maps and institutional affiliations.

Copyright: (c) 2021 by the authors. Licensee MDPI, Basel, Switzerland. This article is an open access article distributed under the terms and conditions of the Creative Commons Attribution (CC BY) license (https:/ / creativecommons.org/licenses/by/ $4.0 /)$.

\begin{abstract}
Herein, we prepared a series of nanocomposite membranes based on chitosan (CS) and three compositionally and structurally different $\mathrm{N}$-doped graphene derivatives. Two-dimensional (2D) and quasi 1D N-doped reduced graphene oxides (N-rGO) and nanoribbons (N-rGONRs), as well as 3D porous $\mathrm{N}$-doped graphitic polyenaminone particles (N-pEAO), were synthesized and characterized fully to confirm their graphitic structure, morphology, and nitrogen (pyridinic, pyrrolic, and quaternary or graphitic) group contents. The largest $(0.07 \%)$ loading of N-doped graphene derivatives impacted the morphology of the CS membrane significantly, reducing the crystallinity, tensile properties, and the $\mathrm{KOH}$ uptake, and increasing (by almost 10-fold) the ethanol permeability. Within direct alkaline ethanol test cells, it was found that CS/N rGONRs (0.07\%) membrane $\left(\mathrm{P}_{\max }=3.7 \mathrm{mWcm}^{-2}\right)$ outperformed the pristine CS membrane significantly $\left(\mathrm{P}_{\max }=2.2 \mathrm{mWcm}^{-2}\right)$, suggesting the potential of the newly proposed membranes for application in direct ethanol fuel cells.
\end{abstract}

Keywords: chitosan; nitrogen-doped reduced graphene oxide; anion-exchange membrane; direct alkaline ethanol fuel cell

\section{Introduction}

The use of environmentally friendly materials to circumvent the steady depletion of fossil fuels, the reduction of global pollution, and electricity consumption, are among the most investigated topics of scientific and technological research in recent decades [1]; all of the above is covered in energy conversion devices, i.e., fuel cells. These are devices that convert chemical energy directly to electrical energy using a fuel that is oxidized (such as natural gas, hydrogen, ethanol, methanol, formic acid, or phosphoric acid), and an oxidizing agents (such as air or oxygen) [2]. As highly efficient, benign, and environmentally friendly devices, fuel cells have been identified as promising and potent technologies for zero emission, electrochemical energy conversion, and power generation, which, apart from their considerable maturation over the last decade, are still constrained by technological barriers, such as insufficient durability and cell life, as well as the high cost of fuel cell components that hamper their commercialization.

For this reason, critical attention has focused increasingly on direct alkaline ethanol fuel cells (DAEFC), where non-noble metal catalysts can be used, together with widely available ethanol, a fuel produced from biomass feedstocks. DAEFCs convert chemical energy stored in liquid ethanol directly into electricity. Non-noble metal cathodes (e.g., perovskite) are robust, and exhibit high tolerance to impurities and fuel crossover through 
the membrane. The main part of the DAEFC is the membrane-electrode assembly (MEA), which is formed by sandwiching the multilayer structure of an anode diffusion layer, an anode-catalyst layer, the anion exchange membrane (AEM), a cathode-catalyst layer and a final cathode diffusion layer. The function of the membrane is to conduct OH(hydroxide) ions from the cathode to the anode, and to separate the anode and cathode electrodes. However, the development of AEM DAEFC suffers from the limitations of the low thermal and chemical stability of AEMs. Since the mobility of hydroxide is only about $57 \%$ of the mobility of a proton, a high ion exchange capacity (IEC) is required to achieve high ion conductivity compared to proton exchange membranes (PEMs) [3]. Currently, commercially available AEMs are based on quaternary ammonium exchange groups, and they are developed by Japan Tokuyama Corporation (Tokyo, Japan) on an unspecified backbone polymer (A201 membrane), Solvay (Beveren, Belgium) on a crosslinked fluorinated polymer (Morgan ADP membrane) and Fumatech, Bietigheim-Bissingen, Germany on polysulfones (FAA membrane) [4].

Synthesis of synthetic polymer AEMs is often complex, environmentally unfriendly, and not cost-effective. Currently, the trend towards bioeconomy and bio-based resource utilization, gives momentum to naturally derived materials also in fuel cells' application, as a part of MEA. One of the most preferred polysaccharide-based biomaterials, in addition to cellulose, is chitosan (CS). CS is non-toxic and thermally stable polymer already found in a prominent place in membranes' development for fuel cells' application. CS is also a biobased polymer, obtained mainly from the exoskeletons of crustaceans and the mycelium of some fungi, which gives it an advantage in production due to its low cost and environmental aspects $[5,6]$. Chitosan as a nitrogen-containing biomass has received much attention for the preparation of nitrogen-doped carbon materials for the oxygen reduction reaction in fuel cells and other electrochemical devices [7]. Vaghari et al. [8] investigated the ionic conductivity of pure CS membranes with different degrees of deacetylation and molecular weight and suggested their suitability for use in alkaline fuel cells. The main flaw of CS, however, is its poor ionic conductivity, which is usually compensated by chemical modification with other functionalities. CS consists of 2-amino-2-deoxy-(1,4)$\beta$-D-glucopyranose units and has a hydrophilic character due to the amino $\left(-\mathrm{NH}_{2}\right)$ and hydroxyl (-OH) groups, both of which allow chemical modification. Recently, CS was modified to form derivatives in which the quaternary ammonium groups are attached [9]. The addition of inorganic components also improved ion conductivity and contributed to the thermal-mechanical properties of the final composite membrane. The introduction of graphene oxide (GO) has been identified to improve mechanical stability, prevent fuel crossover and swelling of the membrane, and improve ionic conductivity due to the $\pi-\pi$ interaction between the aromatic chain of reduced GO $(\mathrm{rGO})$ and the polymer backbone. Strong hydrogen bonds and electrostatic attraction between negatively charged GO plates and positively charged polysaccharide CS groups make CSGO a stable nanocomposite with excellent mechanical and thermal properties [10].

Depending on the type of ionic conductivity within the structure of the polymers, AEMs are divided into polyelectrolyte- consisting essentially of ionomer, and alkali-doped polymer membranes, consisting of an electronegative heteroatom as nitrogen. In recent years, a variety of AEMs have been prepared by the introduction of quaternary ammonium (QA), imidazolium, guanidinium, phosphonium groups, or permethyl cobaltocenium into various polymer backbones, such as poly(styrene), poly(vinyl alcohol), poly(phenylene oxide), poly(arylene ether ketone), and poly(arylene ether sulfone) [11]. In a previous article [12], our group used GO with oxygen functional groups (epoxy, carboxy, keto, hydroxy, etc.), which are similar to poly(styrene), poly(vinyl alcohol), poly(phenylene oxide), and poly(arylene ether ketone).

The presented work demonstrates the processing and introduction of three, compositionally and structurally different types of $\mathrm{N}$-doped graphene derivatives into a CS membrane, forming a self-standing, organic-inorganic nanocomposite membrane. Herein, we hypothesize that introduction of two-dimensional (2D) and quasi 1D N-doped reduced 
graphene oxides (N-rGO) and 3D porous $\mathrm{N}$-doped graphitic particles with nitrogen functional groups: pyridinic $\mathrm{N}$, pyrrolic $\mathrm{N}$, and quaternary or graphitic $\mathrm{N}$ within CS membrane, will enhance its ultimate performance in alkaline fuel cells. The comprehensive study was applied to assess the physicochemical integration between components, the micro structuring, mechanical profile, ethanol permeability, and alkaline uptake, as well as membranes feasibility within application-relevant cell performance test.

\section{Materials and Methods}

\subsection{Materials}

Graphite (Imerys, Timrex PP44, Bodio, Switzerland), multi-walled carbon nanotubes (MWCNTs )(NanoTechLabs C-Grade MWNTs, Yadkinville (NC), USA), $\mathrm{H}_{2} \mathrm{SO}_{4}$ (SigmaAldrich, Darmstadt, Germany, ACS reagent, 95-98\%), $\mathrm{H}_{3} \mathrm{PO}_{4}$ (Sigma-Aldrich, Darmstadt, Germany, ACS reagent, $\geq 85$ wt. $\%$ in $\mathrm{H}_{2} \mathrm{O}$ ), $\mathrm{KMnO}_{4}$ (Sigma-Aldrich, Darmstadt, Germany, ACS reagent, $\geq 99 \%$ ), $\mathrm{H}_{2} \mathrm{O}_{2}$ (Sigma-Aldrich, Darmstadt, Germany, contains inhibitor, 30 wt.\% in $\mathrm{H}_{2} \mathrm{O}$, ACS reagent), $\mathrm{HCl}$ (Sigma-Aldrich, Darmstadt, Germany, ACS reagent, $37 \%$ ), chitosan (CS, degree of deacetylation: $90 \%$, molecular weight: $50-100 \mathrm{kDa}$ ) was purchased in powder form with particle sizes below $200 \mu \mathrm{m}$ from Biolog Heppe $\mathrm{GmbH}$, Landsberg, Germany. Magnesium hydroxide $\left(\mathrm{Mg}(\mathrm{OH})_{2}\right)$ nanopowder, sodium hydroxide $(\mathrm{NaOH})$, ethanol $(\mathrm{EtOH})$ and potassium hydroxide $(\mathrm{KOH})$ were purchased from SigmaAldrich, Darmstadt, Germany. All chemicals were used as received. For the single cell test, the following materials were used: $\mathrm{KOH}$ (Sigma Aldrich, 1.0 M Fixanal $1 \mathrm{~L}$ Ampoule), 2-Propanol (Roth, 99.9\% p.a.), anion exchange ionomer (Fumion FAA-3 solution in NPM, $10 \%$, Bietigheim-Bissingen, Germany), PtRu/C catalyst (HiSPEC 10000, Platinum, nominally $40 \%$, Ruthenium, nominally $20 \%$ on carbon black, Johnson Matthey, London, UK).

\subsection{Preparation of Graphene Oxide (GO) and Graphene Oxide Nanoribbons (GONRs)}

GO and GONRs were synthesized according to a slightly modified previously published method [13]. A mixture of concentrated $\mathrm{H}_{2} \mathrm{SO}_{4} / \mathrm{H}_{3} \mathrm{PO}_{4}$ (vol. ratio $\left.=9: 1\right)(1000 \mathrm{~mL}: 111 \mathrm{~mL})$ was added to the graphite (Imerys, Timrex PP44) (20 g) or MWCNTs (NanoTechLabs C-Grade MWNTs) (20 g) to a mixture of concentrated $\mathrm{H}_{2} \mathrm{SO}_{4} / \mathrm{H}_{3} \mathrm{PO}_{4}$ (vol. ratio $\left.=9: 1\right)(600 \mathrm{~mL}: 67 \mathrm{~mL})$ and then $\mathrm{KMnO}_{4}$ in aliquots ( 6 or 7 aliquots $\times 20 \mathrm{~g}$ ) was added while stirring, producing a slight exotherm to $35-40{ }^{\circ} \mathrm{C}$. The reaction mixture was then stirred using a mechanical stirrer at room temperature in an open $3 \mathrm{~L}$ beaker for 10 days. The reaction mixture was then poured onto ice $(800 \mathrm{~mL}$ or $1000 \mathrm{~mL})$ and 30 vol. $\% \mathrm{H}_{2} \mathrm{O}_{2}(15$ or $20 \mathrm{~mL})$ was added dropwise until the color changed from purple to yellow. For workup, the mixture was transferred to plastic centrifuge bottles, diluted with $\mathrm{H}_{2} \mathrm{O}$, and centrifuged ( $4100 \mathrm{rpm}$ for $30 \mathrm{~min}$ ). The supernatant was decanted away and the remaining solid was washed with $\mathrm{H}_{2} \mathrm{O}$ and centrifuged (4100 rpm for $30 \mathrm{~min}$ ). After the supernatant was removed, the remaining material was washed and centrifuged (4100 rpm for $90 \mathrm{~min}$ ) in succession with $10 \% \mathrm{HCl}$ and $\mathrm{H}_{2} \mathrm{O}$. After this multiple wash, the remaining material was freeze-dried and stored at room temperature.

\subsection{Polyenaminone (4ca)}

Poly(2-(3-aminopropenoyl)-6-\{3-[(1,3-phenylene)amino]propenoyl\}pyridine) (4ca) was prepared following the general literature protocol for the synthesis of a related polyenaminones [14]. A mixture of (2E,2'E)-1,1'-(pyridine-2,6-diyl)bis(3-(dimethylamino)prop2-en-1-one) (2c) (273 mg, $1 \mathrm{mmol})$, 1,3-phenylenediamine dihydrochloride (3a) (181 mg, $1 \mathrm{mmol})$, and methanol $(10 \mathrm{~mL})$ was shaken on an orbital shaker (400 r.p.m.) at room temperature for $96 \mathrm{~h}$. The precipitate was collected by filtration, washed with methanol $(2 \mathrm{~mL})$, and air-dried to give $4 \mathrm{ca}$ as an orange solid in a quantitative yield.

2.4. Nitrogen-Doped Reduced Graphene Oxide (N-rGO) and Nitrogen-Doped Reduced Graphene Oxide Nanoribbons ( $N-r G O N R s)$

$\mathrm{GO}$ and GONRs were heat treated in an $\mathrm{NH}_{3}$ atmosphere (constant flow $30 \mathrm{~mL} / \mathrm{min}$ ) in a quartz tube by using the following heat treatment protocol: (i) room temperature 
to $800{ }^{\circ} \mathrm{C}$ (heating rate $10 \mathrm{~K} / \mathrm{min}$ ); (ii) hold at $800{ }^{\circ} \mathrm{C}$ for $10 \mathrm{~min}$; (iii) $800{ }^{\circ} \mathrm{C}$ to room temperature (cooling rate $20 \mathrm{~K} / \mathrm{min}$ ). The products of pyrolysis in $\mathrm{NH}_{3}$ were labelled as $\mathrm{N}$-rGO and N-rGONRs.

\subsection{Pyrolysis of Polyenaminone (4ca) to Graphitic N-Polyenaminone ( $N-p E A O$ )}

Polyenaminone (4ca) was heat treated in an $\mathrm{N}_{2}$ atmosphere (constant flow $30 \mathrm{~mL} / \mathrm{min}$ ) in a quartz tube by using the following heat treatment protocol: (i) room temperature to $800{ }^{\circ} \mathrm{C}$ (heating rate $10 \mathrm{~K} / \mathrm{min}$ ); (ii) hold at $800{ }^{\circ} \mathrm{C}$ for $10 \mathrm{~min}$; (iii) $800{ }^{\circ} \mathrm{C}$ to room temperature (cooling rate $20 \mathrm{~K} / \mathrm{min}$ ). The product of pyrolysis was labelled as $\mathrm{N}$-pEAO.

\subsection{Preparation of $C S$ and $C S / N-r G O(r G O N R s, p E A O)$ Membranes}

CS membranes were prepared out of $1 \mathrm{wt} . \%$ CS solution in Milli-Q with the addition of $1 \mathrm{M} \mathrm{HCl}$ to $\mathrm{pH}=2-2.5$. Under constant stirring, the CS was completely dissolved, and to obtain CS neutralization, the $\mathrm{pH}$ was again raised to $6-6.5$ by adding $1 \mathrm{wt} . \%$ Milli-Q water dispersion of magnesium hydroxide $\left(\mathrm{Mg}(\mathrm{OH})_{2}\right)$. Final dispersion was allowed to stir at $500 \mathrm{~min}^{-1}$ overnight to allow the $\mathrm{pH}$ stabilization $(\mathrm{pH}$ ). Membranes were prepared by pouring the $25 \mathrm{~mL}$ dispersion into petri dishes with $\mathrm{d}=90 \mathrm{~mm}$ and left to air-dry. The completely dry membranes were neutralized with $1 \mathrm{M} \mathrm{NaOH}$ and then washed several times with distilled water and left to re-dry in air.

For preparation of the CS/N-rGO membranes, the $1 \mathrm{wt} . \% \mathrm{~N}$-rGO, pre-dispersed in Milli-Q water was added to $25 \mathrm{~mL}$ of $1 \%$ CS dispersion, to final concentration of $0.01 \%, 0.04 \%$ and $0.07 \% \mathrm{w} / \mathrm{v}$. Final dispersion was vortexed at $2500 \mathrm{~min}^{-1}$ to obtain a homogeneous dispersion. CS/N-rGO membranes were processed further following the same procedures as described for neat CS membranes, and all membranes were fridgestored until the following characterizations.

\subsection{Characterization}

\subsubsection{X-ray Photoelectron Spectroscopy (XPS) Analysis}

XPS measurements were performed using a SPECS PHOIBOS 150 Hemispherical

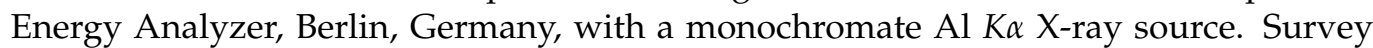
spectra were measured using a pass energy of $40 \mathrm{eV}$ at a resolution of $0.2 \mathrm{eV} \mathrm{step}^{-1}$ and a total integration time of $0.2 \mathrm{~s}$ point $^{-1}$. Core-level spectra were measured using a pass energy of $20 \mathrm{eV}$ at a resolution of $0.05 \mathrm{eV}$ step $^{-1}$ and a total integration time of $0.5 \mathrm{~s} \mathrm{point}^{-1}$. Deconvolution was performed using CasaXPS software (http:/ /www.casaxps.com/) with a Shirley-type background and 70-30 Gaussian-Lorentzian peak shapes. In general, spectra were charge referenced using the position of the $\mathrm{C} 1 \mathrm{~s}$ at $284.0 \mathrm{eV}$.

\subsubsection{Scanning Electron Microscopy (SEM) and Energy-Dispersive X-ray Spectroscopy} (EDS) Analysis

Microstructure characterization of N-rGO and N-rGONRs and N-pEAO was performed by a scanning field emission electron microscope, Zeiss ULTRA plus SEM - Jena, Germany. Samples were adhered to the conductive carbon tape placed on an aluminum SEM holder. SEM images were taken at $2 \mathrm{kV}$ using an SE2 detector at WD $5.5 \mathrm{~mm}$. Further, elemental analysis of the samples was done inside SEM using EDS analysis with an Oxford X-Max SDD detector - High - Wycombe, UK, with working surface area of $50 \mathrm{~mm}^{2}$, processed with INCA software - Wycombe. EDS analysis was done at $20 \mathrm{kV}$.

For visualization of membranes' microstructure, the field emission (FE)-SEM analysis was performed using a Carl Zeiss FE-SEM SUPRA 35 VP electron microscope. Imaging was performed at $1 \mathrm{kV}$ accelerating voltage at an approximately $4.5 \mathrm{~mm}$ working distance. The membranes were attached to aluminum sample holders via conductive carbon adhesive tape. Prior to analysis, a layer of palladium was sputtered on the surface of membrane samples. 


\subsubsection{Brunauer-Emmett-Teller (BET) Analysis}

Specific surface area $\left(\mathrm{m}^{2} / \mathrm{g}\right)$ was measured by $\mathrm{N}_{2}$ adsorption at $77 \mathrm{~K}$ on an ASAP 2020 Micromeritics instrument, Norcross, GA, USA, by using the Brunauer-Emmett-Teller (BET) analysis method. Samples were degassed under vacuum ( 5 millitorrs) at $120{ }^{\circ} \mathrm{C}$ for $2 \mathrm{~h}$.

\subsubsection{Evolved Gas Analysis (EGA) by Thermogravimetric Analysis/Mass Spectrometry (TGA-MS)}

Thermogravimetric measurements were performed on a Netzsch 449 F3 Jupiter, Selb, Germany, instrument under a dynamic Ar (5.0) flow with a flow rate of $60 \mathrm{~mL} \mathrm{~min}^{-1}$ in a temperature range from $30^{\circ} \mathrm{C}$ to $900{ }^{\circ} \mathrm{C}$. A heating rate of $10 \mathrm{~K} \mathrm{~min}^{-1}$ was used. About $15 \mathrm{mg}$ of sample was placed in an alumina $\left(0.3 \mathrm{~mL} \mathrm{Al}_{2} \mathrm{O}_{3}\right)$ crucible. Simultaneously, mass spectrometry was performed on an MS 403C Aëolos with an SEM Chenneltron detector, Selb, Germany, and system pressure of $2 \times 10^{-5}$ mbar. Gases that evolved under TG heat treatment were transferred to the mass spectrometer through a transfer capillary, quartz ID $75 \mu \mathrm{m}$, which was heated up to $220^{\circ} \mathrm{C}$. The upper limit of the mass spectrometer detector was 100 AMU.

\subsubsection{C, H, N Elemental Analysis}

Microanalyses were performed by combustion analysis on a Perkin-Elmer CHN Analyzer 2400 II, Rodgau, Germany.

\subsection{6. $\zeta$ Potential Measurement}

The $\zeta$ potential measurements were conducted on N-rGO, N-rGONRs, and N-pEAO dispersions, using a Nano ZS ZEN360 (Malvern Instruments Ltd., Malvern, UK). Each dispersion was prepared at a concentration of $0.001 \mathrm{wt} . \%$, using Milli-Q water as a dispersant, applying intensive stirring and $1 \mathrm{~h}$ ultrasonication. The $\zeta$ potential values were obtained over the $\mathrm{pH}$ range of 2 to 12 . The average values and Standard Deviations were calculated from at least three individual measurements.

\subsubsection{Attenuated Total Reflectance-Fourier Transform Infrared (ATR-FTIR) Spectroscopy}

ATR-FTIR spectra were obtained on a Spectrum One FTIR spectrometer (Perkin-Elmer) with a Golden Gate ATR attachment and a diamond crystal for all components, as well as CS membranes, containing variable concentrations of N-rGO, N-rGONRs, and N-pEAO. The absorbance measurements were recorded within the $650-4000 \mathrm{~cm}^{-1}$ region, with 16 scans and a resolution of $4 \mathrm{~cm}^{-1}$.

\subsubsection{X-ray Diffraction Spectroscopy (XRD)}

XRD patterns of the membranes were recorded on a D2 X-ray diffractometer (Bruker Siemens). Reflections at $2 \theta$ were observed between the range $5^{\circ}$ and $70^{\circ}$, with an increment of $0.03^{\circ}$, using a Si holder at a voltage of $30 \mathrm{kV}$ and current of $10 \mathrm{~mA}$. The relative crystallinity degree of the polymer phase was determined by the ratio between the integrated area of the crystalline peaks and the integrated total area of the diffraction spectra [15].

\subsubsection{Mechanical Testing}

CS/N-rGO, N-rGONRs, and N-pEAO membranes were analyzed by a Shimadzu, AG-X plus $10 \mathrm{kN}$ electromechanical universal testing machine. Membrane samples with specimen dimensions: $10 \mathrm{~mm} \times 20 \mathrm{~mm}$ were mounted vertically. The effective clamping distance was $25 \mathrm{~mm}$. Application of a tensile force $(10 \mathrm{kN}$ load cell $)$ proceeded at $1 \mathrm{~mm} / \mathrm{min}$. Two specimens were tested per sample, and average values and standard deviations were calculated. Prior to testing, the membranes were equilibrated in distilled water for $3 \mathrm{~h}$. The tensile modulus (MPa), tensile strength ( $\mathrm{MPa}$ ) and elastic elongation (\%) were calculated from the stress/strain data curves from respective membranes. 


\subsubsection{KOH Uptake and In-Plane Swelling}

$\mathrm{KOH}$ uptake and a swelling test of membranes was performed in $6 \mathrm{M} \mathrm{KOH}$ at $60^{\circ} \mathrm{C}$. Membrane samples of $1 \times 1 \mathrm{~cm}^{2}$ were weighted, and their surface areas were measured, before $\left(\mathrm{W}_{\mathrm{dry}}, \mathrm{A}_{\mathrm{dry}}\right.$, respectively) and after immersion in $6 \mathrm{M} \mathrm{KOH}\left(\mathrm{W}_{\text {wet }}, \mathrm{A}_{\mathrm{we}} \mathrm{t}\right.$, respectively), where the surplus alkaline solution on the membrane surface was blotted with tissue paper. Measurements were performed after $1 \mathrm{~h}, 2 \mathrm{~h}$, and $24 \mathrm{~h}$ of immersion. Accordingly, $\mathrm{KOH}$ uptake (\%) and in-plane swelling (\%) were determined by the following Equations (1) and (2):

$$
\begin{gathered}
\text { KOH uptake }(\%)=\frac{W_{\text {wet }}-W_{d r y}}{W_{d r y}} \times 100 \\
S R_{\text {In-plane }}=\frac{A_{\text {wet }}-A_{d r y}}{A_{d r y}} \times 100
\end{gathered}
$$

\subsubsection{Ethanol Permeability}

Ethanol permeability through a $1 \%$ CS membrane with N-rGO, N-rGONRs, and $\mathrm{N}$-pEAO was measured in a temperature probe at $25^{\circ} \mathrm{C}$ in two temperature-controlled diffusion cells. The membrane, with an area of $66.04 \mathrm{~cm}^{2}$, was located between the two temperature-controlled diffusion cells (the volume of each cell unit was $25 \mathrm{~mL}$ ). Reservoir A was filled with $25 \mathrm{~mL}$ of $6 \mathrm{M} \mathrm{KOH}$, reservoir B was filled with $25 \mathrm{~mL}$ of $2 \mathrm{M} \mathrm{EtOH} / 6 \mathrm{M}$ $\mathrm{KOH}(8.5 \mathrm{w} / \mathrm{w} \%$ ethanol). To create the same pressure on the membrane, we filled both reservoirs at the same time, as this represents the natural working environment of the fuel cell. The ethanol concentration was determined using a conductometer at different time intervals. The ethanol permeability $(P)$ was calculated according to Equation (3):

$$
P\left(\frac{c m^{2}}{s}\right)=\frac{\left(C_{B}-C_{B 0}\right)}{\left(t-t_{0}\right)} \times \frac{V_{B} l}{A C_{A 0}}
$$

where $\left(C A_{0}\right.$ is the initial concentration of ethanol in reservoir $\left(B\right.$, and $\left(V_{B}\right.$ is the volume of $\mathrm{KOH}$ in reservoir $\mathrm{A}$. A represents the surface of the membrane and $\mathrm{L}$ is the thickness of the membrane.

2.7.12. Cell Performance Measurement (Single Cell Testing, DAEFC Performance with CS-GO Membranes)

The DAEFC performance of the pristine CS, CS/N-rGO, CS/N-rGONRs, and CS/NpEAO membranes was investigated via single cell tests. Prior to the fuel cell experiments, the membranes were doped with $\mathrm{OH}$ - by immersion in $1 \mathrm{M} \mathrm{KOH}$ (1.0 M Fixanal $1 \mathrm{~L}$ Ampoule, Sigma Aldrich, Darmstadt, Germany) for $24 \mathrm{~h}$ and extensive washing with distilled water. Electrodes were developed by depositing ink slurries of the anode/cathode catalysts to the gas diffusion layer (GDL) using an automatic ultrasonic spray coater from Sono-Tek. The catalyst ink was prepared by dispersing the electrocatalysts in a mixture of 2-propanol (99.9\% p.a., Roth) and distilled water (7:3) containing $30 \mathrm{wt} . \%$ of a commercial anion exchange ionomer (fumion ${ }^{\circledR}$ FAA-3 solution in NPM, $10 \%$ ). The cathode was prepared by spraying the ink slurry of a commercial PtRu/C catalyst (Platinum, nominally 40\%, Ruthenium, nominally $20 \%$ on carbon black, HiSPEC ${ }^{\circledR} 10000$ ) onto a carbon paper as GDL (Sigracet 29 BC, fuel cell store, $0.235 \mathrm{~mm}$ thick), whereas an ink of a PdNiBi/C catalyst synthesized by the modified instant reduction method [16] was sprayed on a carbon cloth (ELAT—hydrophilic plain cloth, fuel cell store, $0.406 \mathrm{~mm}$ thick) to fabricate the anode. The electrode preparation resulted in a metal loading of $0.5 \mathrm{mg} \mathrm{cm}^{-2}$ for the cathode and $0.75 \mathrm{mg} \mathrm{cm}^{-2}$ for the anode. The membrane electrode assemblies (MEAs) with a size of $2 \times 2 \mathrm{~cm}^{2}$ were prepared by placing the membrane electrolyte between the electrodes. The MEAs were assembled carefully in a self-constructed DAEFC. Pure oxygen gas (5.0, 99.995\%) with a constant flow rate of $25 \mathrm{~mL} \mathrm{~min}^{-1}$ was used as a cathode feed gas. A mixture of $1 \mathrm{M}$ ethanol in $1 \mathrm{M} \mathrm{KOH}$ served as anode fuel $\left(5 \mathrm{~mL} \mathrm{~min}^{-1}\right)$. The membranes doped with $\mathrm{N}$-rGONRs and $\mathrm{N}$-pEAO were tested additionally in $3 \mathrm{M} \mathrm{EtOH} / 5 \mathrm{M} \mathrm{KOH}$ to determine the influence of the fuel concentration on the cell performance. The measurements were generally conducted at room temperature 
for all graphene doped membranes and a chitosan reference membrane, to investigate the influence of the graphene concentration $(0 \%, 0.01 \%, 0.04 \%, 0.07 \%)$ in the samples on the DAEFC performance. To evaluate the temperature dependence, experiments were also conducted at higher temperatures $\left(35^{\circ} \mathrm{C}, 43^{\circ} \mathrm{C}, 50^{\circ} \mathrm{C}\right.$, and $\left.57^{\circ} \mathrm{C}\right)$. The current densities (I) and cell potentials (V) of the single cells were determined using a Reference 600TM Potentiostat/Galvanostat/ZRA from Gamry Instruments - Warminster, PA, USA. The results were plotted in a current density - potential (I-V) diagram, with additional indication of the power density.

\section{Results and Discussion}

\subsection{Synthesis and Characterizations of N-rGO, N-rGONRs, and N-pEAO}

The resulting properties of polymer/graphene composites can be affected by the type of graphene used, its specific surface area, dispersibility in a polymer matrix, interfacial interactions, surface functionalities, the processing method, etc. [17]. In this respect, we have synthesized 3-representative types of nitrogen doped graphene derivatives, i.e., 2D nitrogen-doped reduced graphene oxide (N-rGO), quasi-1D nitrogen-doped reduced graphene oxide nanoribbons (N-rGONRs), and 3D N-polyenaminone (N-pEAO). Graphenebased materials N-rGO and N-rGONRs were synthesized by a two-step reaction starting using graphite and multi-walled carbon nanotubes (MWCNTs), respectively. The first step was a wet chemistry, top-down approach-a modified Hummers to yield GO and GONRs. GO and GONRs were subsequently reduced and doped with nitrogen in an NH3 atmosphere to yield N-rGO and N-rGONRs. Graphitized N-polyenaminone (N-pEAO) was synthesized in a two-step reaction employing a wet chemistry bottom-up approach. In the first step, polyenaminone (4ca) was synthesized by acid-catalyzed amino-enaminone "click" polymerization reaction $[14,18]$. Such polymer with inherently layered morphology (Figure S1) was then, in a second step, pyrolyzed in an inert atmosphere to yield graphitic $\mathrm{N}$-polyenaminone ( $\mathrm{N}$-pEAO). All three $\mathrm{N}$-doped materials exhibited a highly defected graphene like structure according to Raman spectroscopy (Figure S2). Raman spectra exhibited representative $\mathrm{D}, \mathrm{G}$ and $2 \mathrm{D}$ peaks.

GO and GONRs possess oxygen functional groups, which were replaced by nitrogen functional groups in N-rGO and N-rGONRs during heat treatment under an $\mathrm{NH}_{3}$ atmosphere. On the contrary, N-pEAO preserves the inherent nitrogen functionalities that are part of the synthetic precursors (Scheme 1).

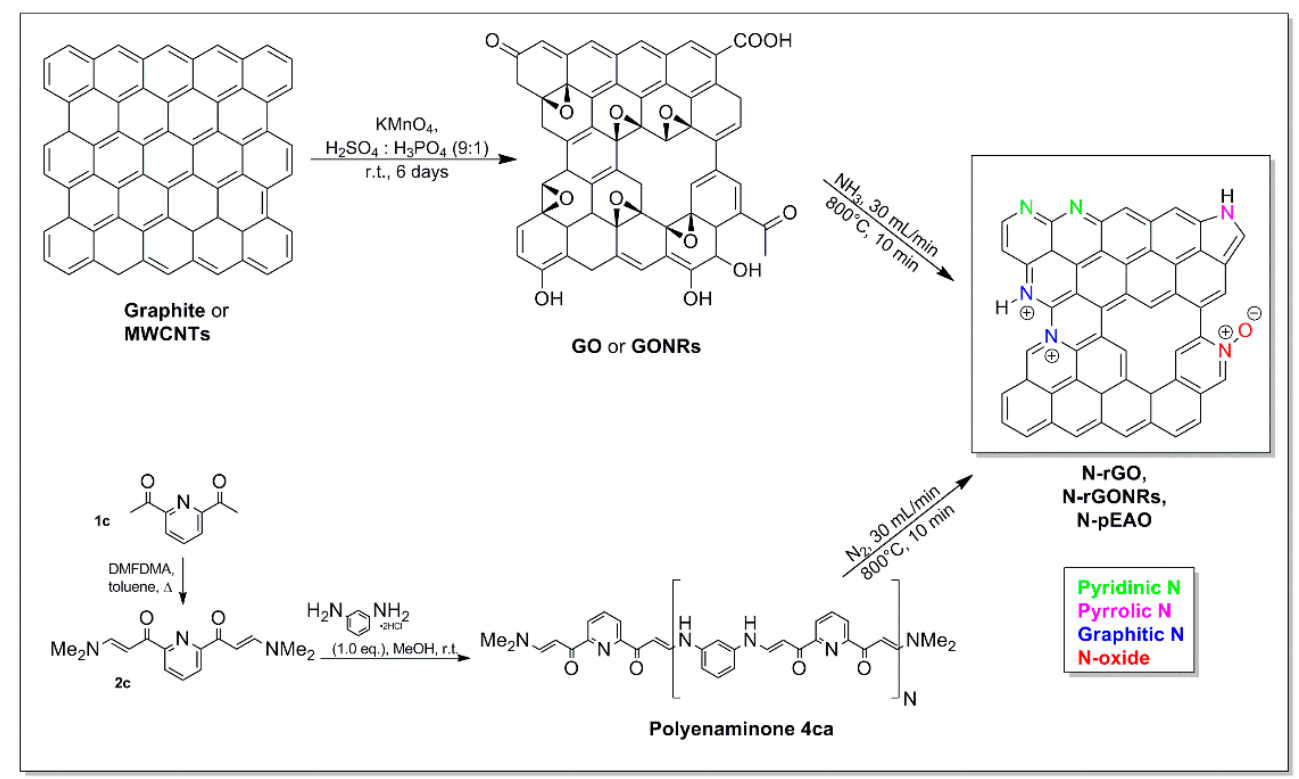

Scheme 1. Synthesis of N-rGO, N-rGONRs, and N-pEAO; a schematic reaction scheme. 
As mentioned above, it is of great importance that, when making a composite membrane, we use graphene-based materials with a high specific surface area and high degree of nitrogen functionalization. These two parameters are responsible for good $\mathrm{OH}$ - conductivity and enhancing mechanical membrane properties. Further, structural defects that are formed in the graphene basal plane during the synthesis should also be beneficial for ionic conductivity properties since they make the material permeable for ion diffusion [19]. Another important parameter is the thermal stability of the membrane and its constituents at the operating temperatures of a fuel cell.

N-rGO, N-rGONRs, and N-pEAO were characterized by SEM for morphological purposes. In Figure 1a, the layered nature of the N-rGO is seen clearly. Flakes are several $\mu \mathrm{m}$ in diameter. Further, N-rGO sheets are crumpled, due to freeze-drying of the GO precursor, although a specific surface area of the $\mathrm{N}-\mathrm{rGO}\left(187.6 \mathrm{~m}^{2} / \mathrm{g}\right)$ was three times larger compared to the GO precursor $\left(37.2 \mathrm{~m}^{2} / \mathrm{g}\right)$. It should be noted that specific surface area of $\mathrm{N}$-rGO is measured in a dry form of material, which is known to restack during drying. However, when material is dispersed in liquid media the layers are delaminated, due to the electrostatic repulsion forces, and the specific surface area should increase significantly. $\mathrm{N}$-rGONRs represent a quasi-1D high aspect ratio derivative of a graphene nanoribbon. The SEM image (Figure 1b) shows nanoribbons various sizes clearly, which are twisted, and the edges wrinkled. The BET specific surface area is $200.3 \mathrm{~m}^{2} / \mathrm{g}$, which was measured again for the freeze-dried sample and is larger than the value for N-rGO. Contrarily, the $\mathrm{N}$-pEAO exhibited a relatively lower BET specific surface area $\left(20.6 \mathrm{~m}^{2} / \mathrm{g}\right)$, although the SEM morphology (Figure 1c) indicates high porosity—sponge-like morphology.
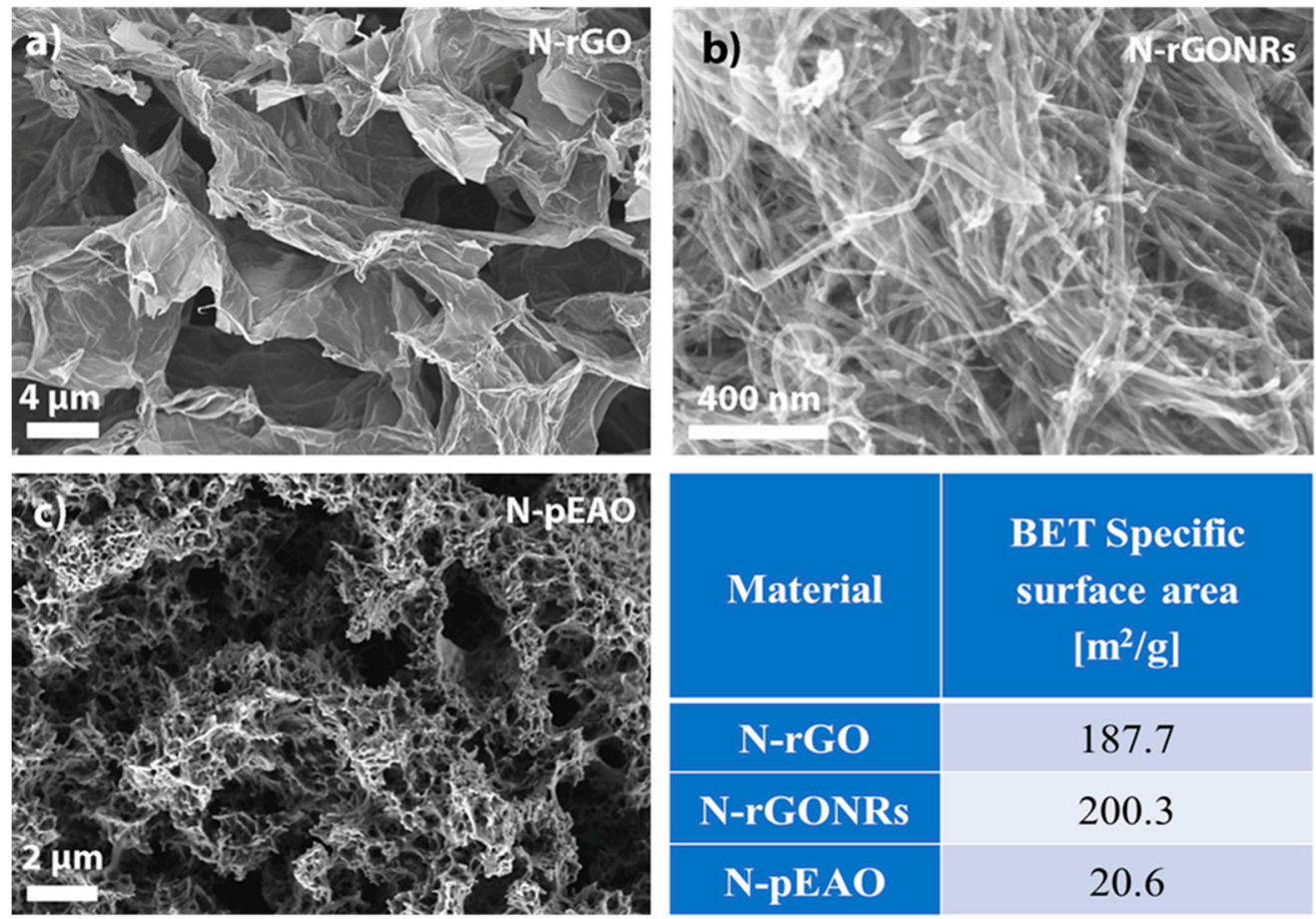

Figure 1. SEM images and Brunauer-Emmett-Teller (BET) specific surface area values of (a) N-rGO, (b) N-rGONRs, and (c) N-pEAO.

To evaluate the nitrogen concentration in N-rGO, N-rGONRs, and N-pEAO, we performed CHN elemental analysis (Figure S3) and XPS analysis (Figure 2). Further, we also estimated the concentration of various nitrogen functional groups by deconvolution of the N1s core-level spectra. Peaks at $397.5 \mathrm{eV}, 398.8 \mathrm{eV}, 400.6 \mathrm{eV}$ in $402.7 \mathrm{eV}$ were assigned to the pyridinic $\mathrm{N}$, pyrrolic $\mathrm{N}$, graphitic $\mathrm{N}$, and $\mathrm{N}$-oxide, respectively. Figure 2a-c reveals two different types of materials relative to the nature of nitrogen functionalities. N-rGO and $\mathrm{N}$-rGONRs have a relatively high concentration of pyridinic $\mathrm{N}$ (above $42 \%$ ) and pyrrolic $\mathrm{N}$ 
(above $26 \%$ ) while $\mathrm{N}$-pEAO has only $30.8 \%$ of pyridinic $\mathrm{N}$ and $10 \%$ of pyrrolic $\mathrm{N}$. Contrarily, the concentration of graphitic $\mathrm{N}$ is $\sim 21 \%$ for $\mathrm{N}-\mathrm{rGO}$ and $\mathrm{N}-\mathrm{rGONRs}$ and $49.5 \%$ for $\mathrm{N}-\mathrm{pEAO}$. This means that N-rGO and N-rGONRs possess predominantly pyridinic $\mathrm{N}$, while N-pEAO possesses predominately graphitic N. Further, the overall concentration according to the $\mathrm{CHN}$ analysis of nitrogen is relatively high for N-rGO and N-pEAO-11 wt.\% and 9.8 wt.\%, respectively (Figure S3). These values are three times higher than the value for $\mathrm{N}$-rGONRs, which is $3 \mathrm{wt} . \%$. XPS survey values for nitrogen overall concentrations are in correspondence with the CHN analysis. We also noticed that, according to the XPS survey, concentrations of oxygen go up to $7.3 \mathrm{wt}$.\% (Figure 2d). Oxygen is either part of the $\mathrm{N}$-oxide functional group or remaining GO, GONRs, or polyenaminone oxygen functional groups, which might form hydrogen bonds with CS-related functional groups, and, thus, form stable composite membranes.
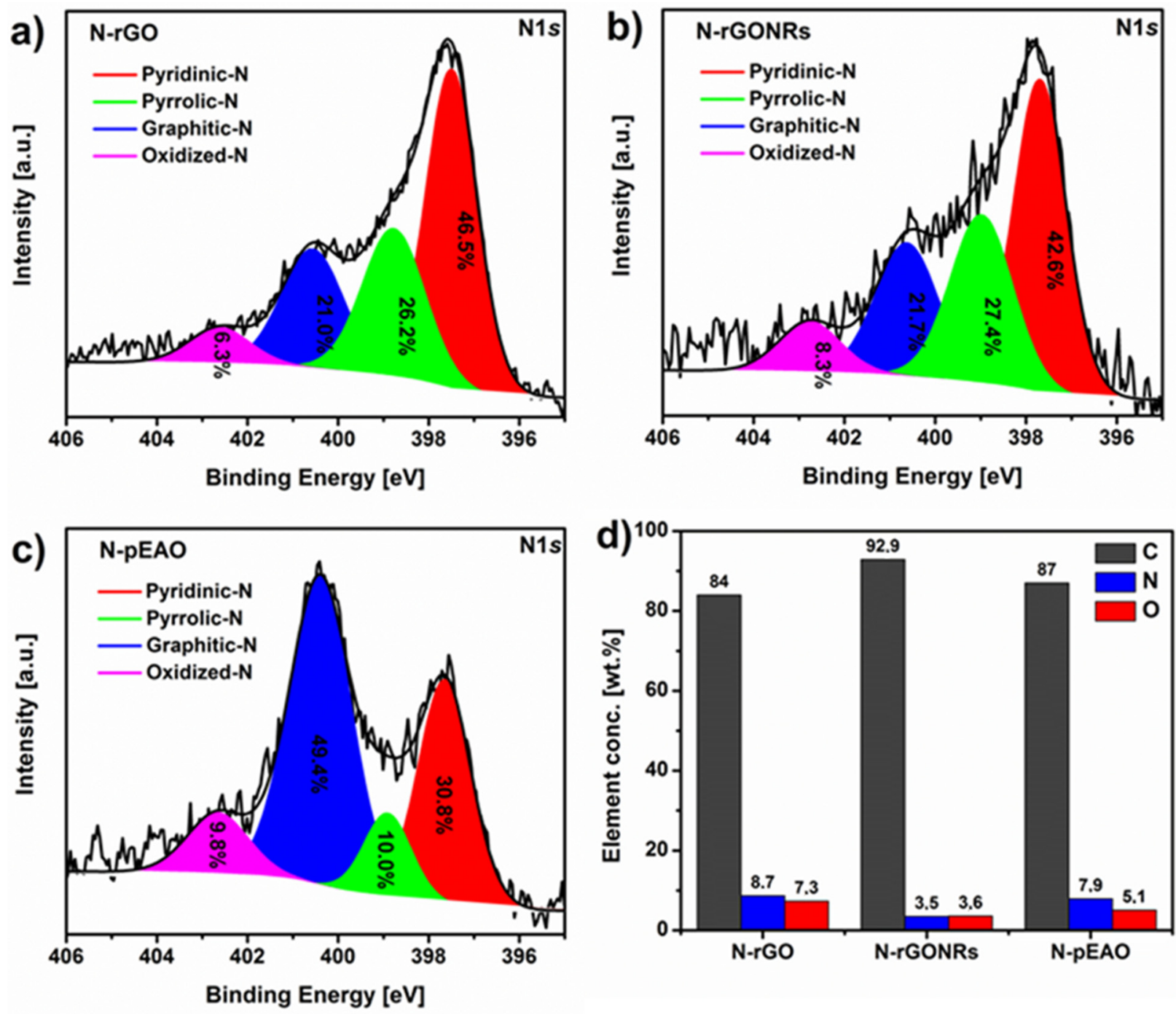

Figure 2. N1s XPS core level spectra with spectral deconvolution and quantified values for (a) N-rGO, (b) N-rGONRs, and (c) N-pEAO, and (d) Corresponding quantified values of C, N, and O from the XPS survey spectra.

For testing the thermal stability of $\mathrm{N}$-doped materials, we performed a TGA experiment under dynamic inert conditions (Figure 3). The decomposition gases were also monitored with a mass spectrometer (MS). The TGA results show that N-rGO, N-rGONRs, and $\mathrm{N}$-pEAO are very stable in a wide temperature range, which is beneficial for the stability of the composite membranes during the fuel cell operation conditions. The total weight loss for N-rGO was $14.1 \mathrm{wt} . \%$, for N-rGONRs $12.5 \mathrm{wt.} \%$ and for N-pEAO 15.9 wt. $\%$. 
Further, we observed water uptake from the atmosphere $\left(\mathrm{H}_{2} \mathrm{O}\right.$ adsorption) for all three materials at low temperature intervals by monitoring the $\mathrm{m} / \mathrm{z} 18$ signal, which correspond to $\mathrm{H}_{2} \mathrm{O}^{+}$evolution. Such a property is beneficial for membrane applications since it can lead to the desired electrolyte-membrane interactions. The amount of adsorbed water was $2.6 \mathrm{wt} . \%$ for N-rGO, $3.3 \mathrm{wt} . \%$ for N-rGONRs and $1.7 \mathrm{wt} . \%$ for N-pEAO. Major weight loss was observed (9.1 wt.\%, $7.3 \mathrm{wt} . \%, 10,1 \mathrm{wt} . \%$ for N-rGO, N-rGONRs, and N-pEAO, respectively) at very high temperatures, where $\mathrm{CO}_{2}$ evolution was in terms of $\mathrm{m} / \mathrm{z} 44$ was the predominant decomposition gas. This was attributed to the further graphitization and defunctionalization of the remaining oxygen functionalities, which were stable up to $800{ }^{\circ} \mathrm{C}$ (maximum pyrolysis temperature in synthesis).
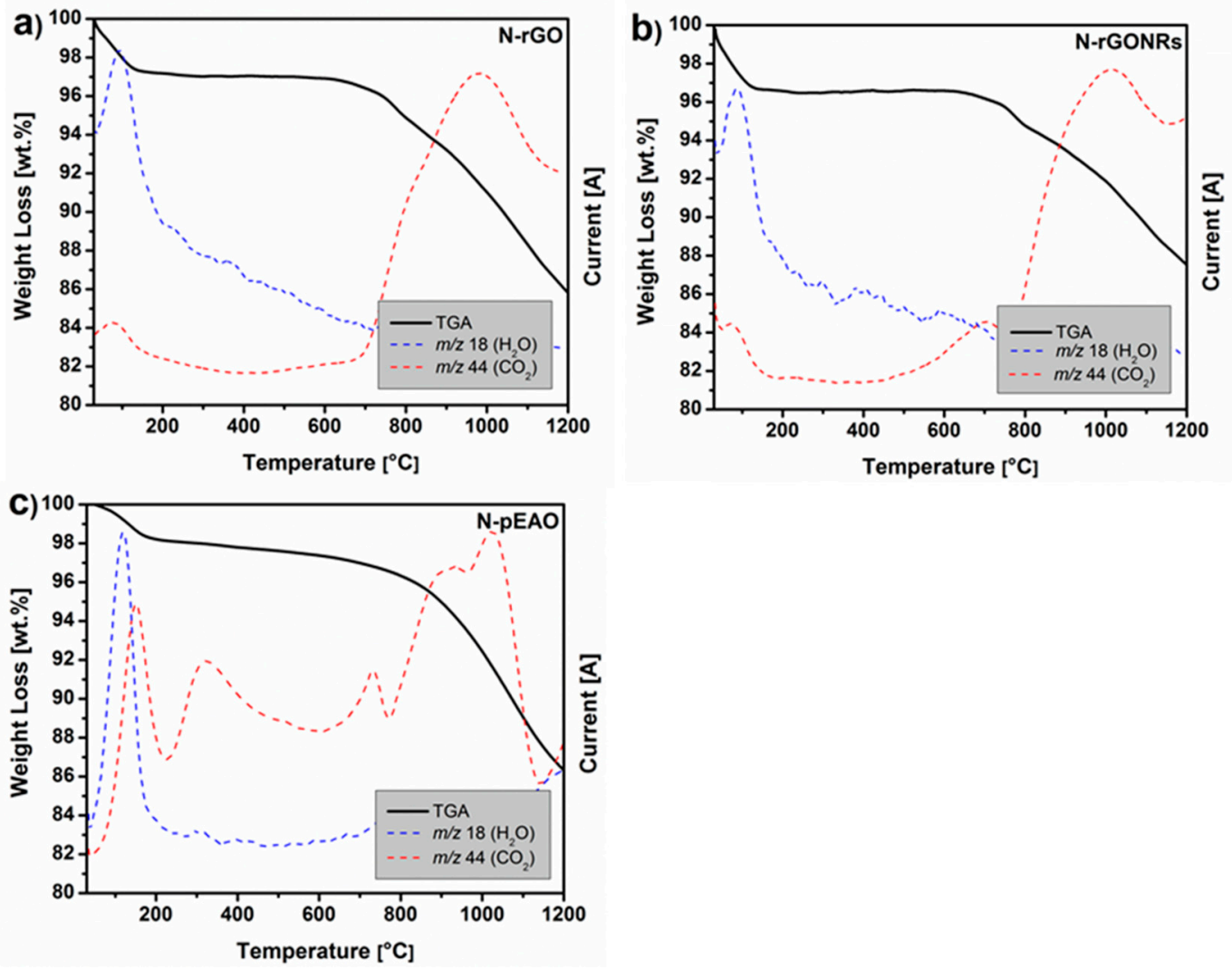

Figure 3. Evolved gas analysis done by TGA (black curve) coupled to MS fragments $m / z 18\left(\mathrm{H}_{2} \mathrm{O}^{+}\right)$ (blue curve) and $m / z 44\left(\mathrm{CO}_{2}^{+}\right)$(red curve) for (a) N-rGO, (b) N-rGONRs, and (c) N-pEAO.

$\mathrm{N}-\mathrm{rGO}, \mathrm{N}-\mathrm{rGONRs}$, and $\mathrm{N}$-pEAO water dispersions were examined further by $\zeta$ potential measurement, which gives an indication of the stability of the colloidal system. The $\zeta$ potential curves in Figure 4 demonstrate the $\mathrm{pH}$-switching phenomenon observed for all three dispersions, which can be explained by the Derjaguin-Landau-Verwey-Overbeek theory of colloidal dispersion. According to this theory, colloids tend to agglomerate or remain discrete, according to the net interaction from van der Waals attractions and electrostatic repulsions [20], where the large charge density increases the stability of dispersions by suppressing the aggregation process. The obtained data suggest the largest stability on terminal $\mathrm{pH}$ values. Moreover, the relatively low $(+10 \mathrm{mV})$ charge density at $\mathrm{pH}$ of mixing with $\mathrm{CS}$ solution ( $\mathrm{pH}$ 6) was measured for N-rGO, N-rGONRs, and N-pEAO particles, which suggests a high probability for aggregation at drying. Having the same net ionization, allow us to exclude this factor when the behavior of differently structured, $\mathrm{N}$-doped graphene derivatives is evaluated in relation to the properties of the final composite membrane. 


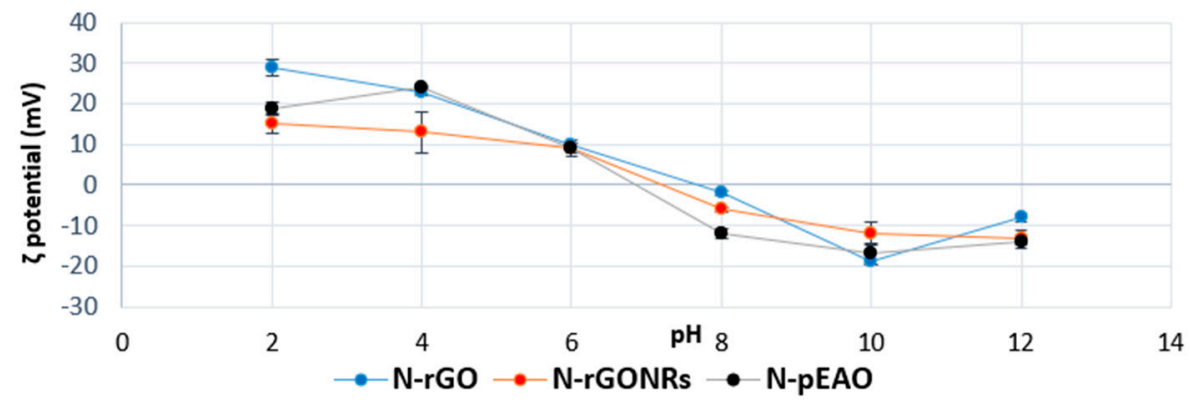

Figure 4. $\zeta$ potential of N-rGO, N-rGONRs, and N-pEAO in the pH range 2-12.

\subsection{Chemical Structure, Crystallinity, and Surface Morphology of CS/Graphene-Based Membranes}

Figure 5 present the FE-SEM images of CS, CS/N-rGO, CS/N-rGONRs, and CS/NpEAO membranes, displaying the appearance of membranes' surface morphology. The structure and morphology of membranes play an important role in ensuring optimal performance of the fuel cells; they influence the conductivity of the system by dictating ion transport, wetting efficiency of the electrolyte, as well as fuel, e.g., ethanol, permeability. Surface morphology further contributes to the operation of the fuel cell, since it can, to a certain degree, even offset the effect of advantageous high conductivity. Our previous study [12] reported that smooth CS membranes pushed the fuel cell performance past samples, which exhibited a more structured and nanoporous surface yet possessed higher conductivity values. The smoothness of the surface was speculated to contribute to a reduction of the interfacial resistance in the membrane electrode assembly, and, thus, resulted in a higher power output.

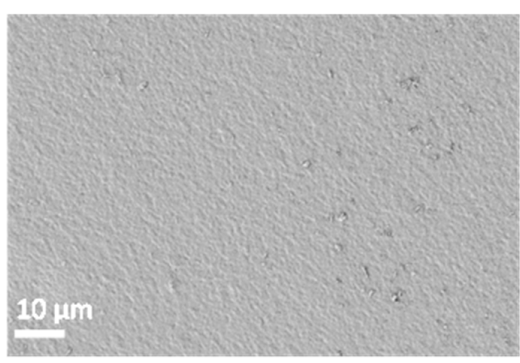

a)

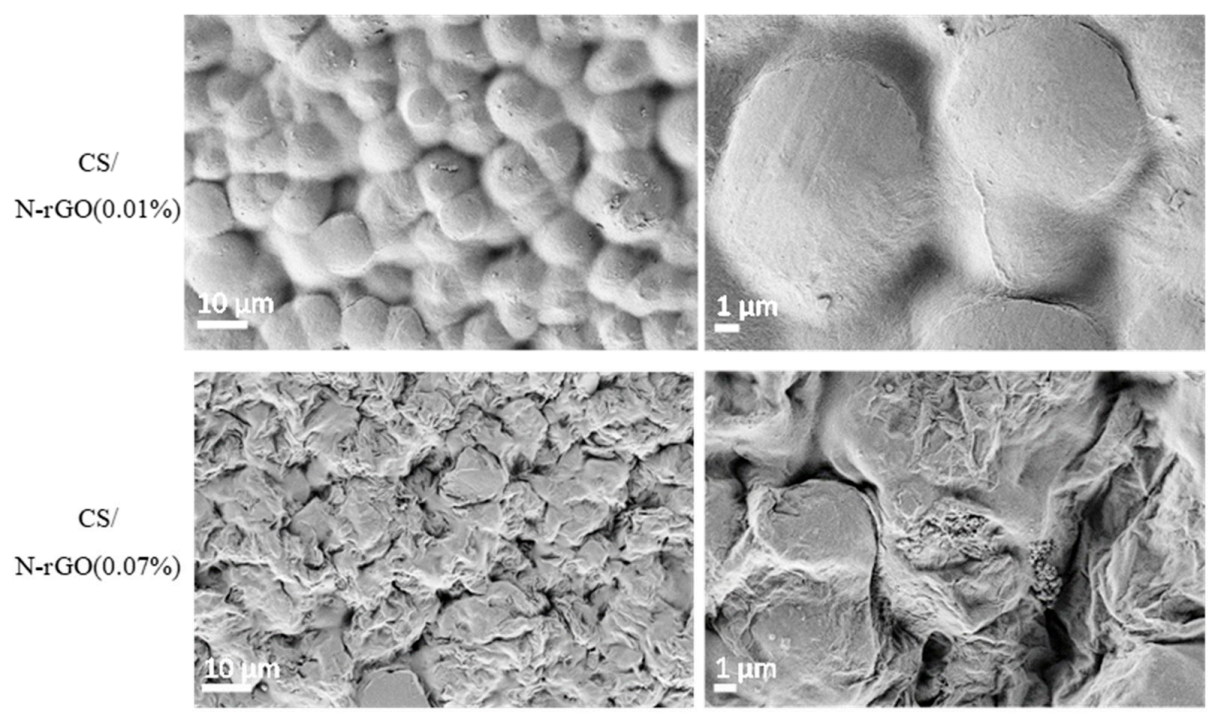

b)

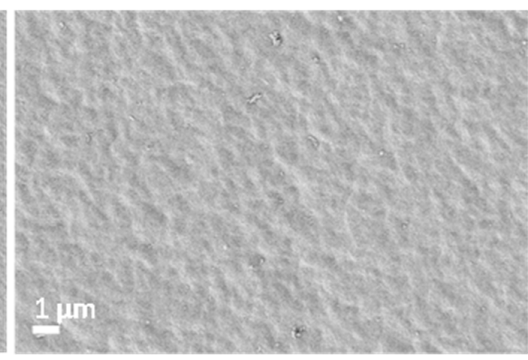

Figure 5. Cont. 


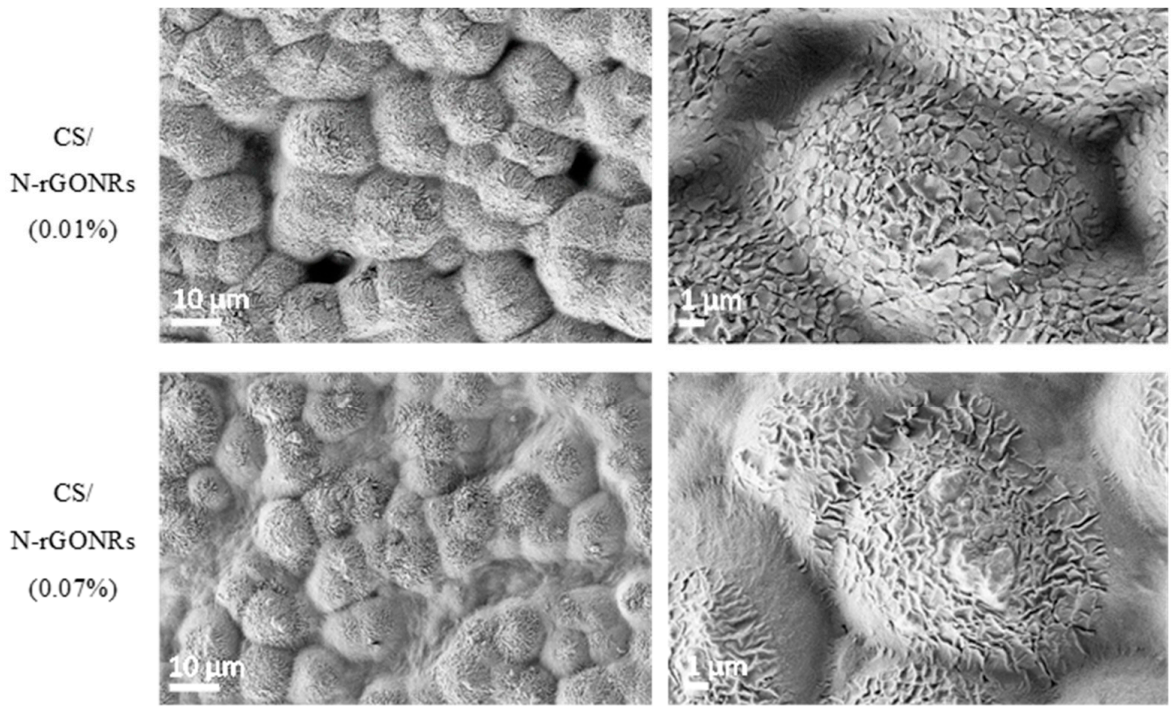

c)

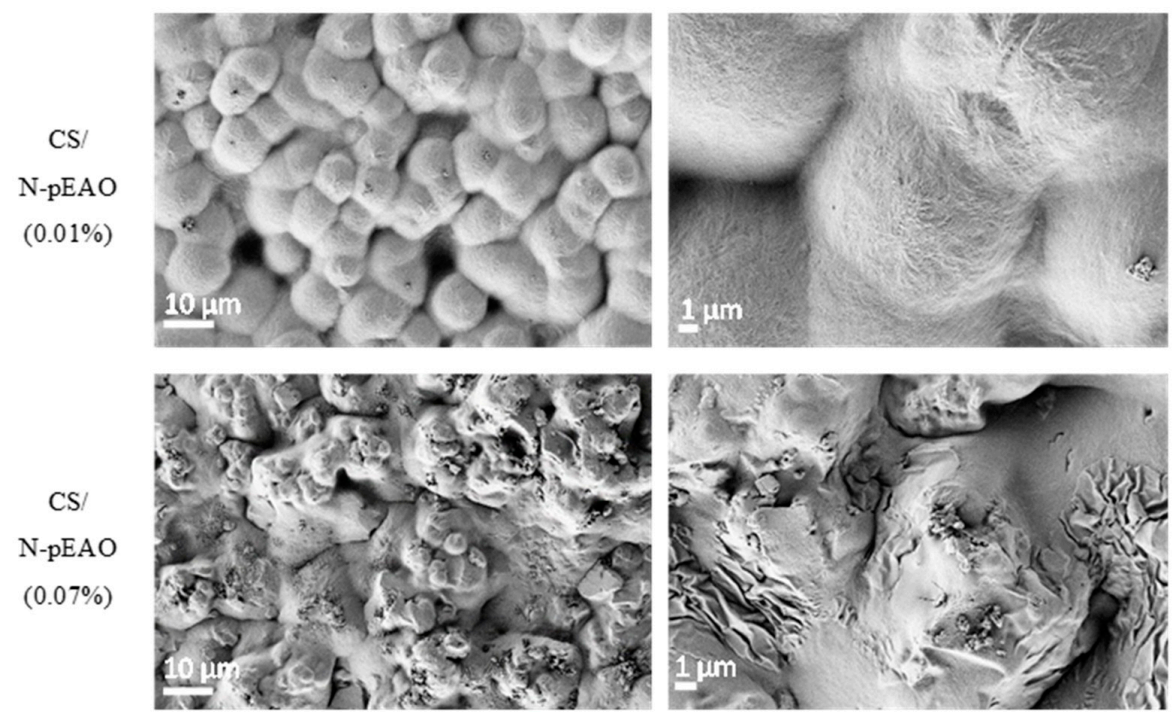

d)

Figure 5. SEM images of (a) chitosan (CS) and CS/graphene-based composites, containing $0.01 \%$ and $0.07 \%$ of (b) N-rGO, (c) N-rGONRs, and (d) N-pEAO.

According to the SEM images (Figure 5), the membranes of CS alone exhibit no discernible structural features (Figure 5a); they possess a non-macroporous, dense film-like structure. CS is well known to form films readily, the physical properties of which are dependent on the concentration of the solution, as well as the type of acid used for the dissolution [21].

The SEM images demonstrate that inclusion of rGO or nitrogen doped graphenebased derivatives into CS polymer matrix cause obvious changes in the morphology of the resulting membranes: The non-structured, homogeneous surface of the polymer film is disturbed to a different degree, depending on the type of graphene-based particle used and its concentration. Morphology of membrane after N-rGO inclusion (Figure 5b) is characterized by a lumpy appearance, with low concentration $(0.01 \%)$ bulging the CS membrane into tightly packed spherical surface artefacts. These, on a micro-level, retain the smooth surface, as visible in the images of higher magnifications. Increasing the concentration of $\mathrm{N}-\mathrm{rGO}$ up to $0.07 \%$ affects the surface morphology in a pronounced way; 
while the bulging overall appearance is still discernible (with deeper grooves among the lumps), and on a micro level one can observe the discrete association of graphene-based particles within the CS matrix. This can be attributed to an increase in concentration from $0.01 \%$ to $0.07 \%$ of particles, and despite that, one can regard the higher value as a still relatively low concentration value for particle inclusion, which does result in limited phase separation. Nonetheless, it must be noted that graphene-based particles are still well embedded and well dispersed within the CS polymer phase.

The membrane set produced with N-rGONRs inclusion into CS (Figure 5c), again exhibited the bulging of the carrier CS membrane, where the ribbon-shaped particles obviously bring about specific structural features on a micro-level. In the case of the lower concentration $(0.01 \%)$, these appear to adopt a flat conformation within the CS polymer membrane, covering the entire surface of the membrane evenly by stacking laterally next to each other, and affording the sample with pores along the sides of the contacting particles. Upon the increase of concentration (up to $0.07 \%$ ) N-rGONRs particles assume a different arrangement, again stemming from the association of particles, as suggested by the $\zeta$ potential data. Particles do not appear in a flat fashion, but rather create a creased film structure, localized on the elevated portions of the membrane surface. Opposite to the previous samples, the CS membranes including N-pEAO particles (Figure 5d) exhibit, regardless of the concentration, a less ordered surface in terms of the bulging effect of the polymer matrix; here, much deeper voids and holes are present. On a micro-level, lower concentration yields a surface, which exhibits a fibrillar-like appearance with particles causing shallow homogeneous ripples within the polymer film. A concentration value of $0.07 \%$ alters the surface morphology drastically, where unevenly shaped and sized lumps appear with randomly scattered agglomerates of N-pEAO particles within the polymer matrix, which is a consequence of their 3D porous shape. On the contrary, the 2D NrGO and quasi-1D N-rGONRs-containing membranes exhibit a homogeneous appearance with evenly distributed structural features encompassing large areas, which reflects the capacity of CS to provide an efficient embedding medium for particle inclusion, as well as performing the function of a supporting substrate on a larger scale, diminishing the possibilities that membranes could fail due to localized inhomogeneity.

XRD was used to identify the crystallinity profile of CS-graphene-based membranes, in particular the effect of the different graphene component on it. The XRD pattern of N-rGO and N-rGONRs (Figure 6a) demonstrate a diffraction peak at the vicinity of $26^{\circ}$, corresponding to an (002) plane typical for thermally reduced GO [22], where there is a small difference in \% crystallinity (only $~ 5 \%$ lower in N-rGONRs compared to NrGO with $50 \%$ crystallinity). The N-pEAOs have broad diffraction in the vicinity of $25^{\circ}$, demonstrating more turbostratic structure as a consequence of the parent compound structure (amorphous, 3D porous) [18].

The molecular organization of CS chains within the membranes is influenced strongly by the processing procedure, type of acids and alkaline solutions used in dissolution and neutralization, respectively, as well as its molecular characteristics, such as the Mw, degree of deacetylation, origin, etc. [24]. The crystallinity of CS is determined by the intramolecular and intermolecular hydrogen bonds of its tertiary structure. The XRD pattern of neat CS membrane (Figure 6a) demonstrates two dominant reflections at $2 \theta=11^{\circ}(020)$ and $2 \theta=18^{\circ}(110)$, which coincide with the pattern of the form I crystal and the form II crystal, respectively. This membrane also has the highest (mean) crystallinity index (53.2\%). In all cases, the addition of graphene-based components reduces the crystallinity. The increase of N-rGO and N-rGONRs concentration (up to $0.07 \%$ ) reduce the crystallinity down to a value of $39.55 \%$ and $36.25 \%$, respectively. This means that crystallization of CS in affected negatively by the presence of N-doped rGO components, which is opposite to the recent findings for CS/GO aerogels [23], due mainly to the use of N-doped rGO and not GO itself. In the case of N-pEAO addition, the order of crystallinity change is opposite, and the same was not influenced significantly by increasing concentration, which we speculate to be due to the 3D macroporosity of N-pEAO (Figure 1c), allowing migration of CS within its 
structure and closer interaction. The latter can be supported by the high magnification SEM images (Figure 5d), revealing smooth (amorphous) film formation at lower and more ordered aggregations at higher loading.

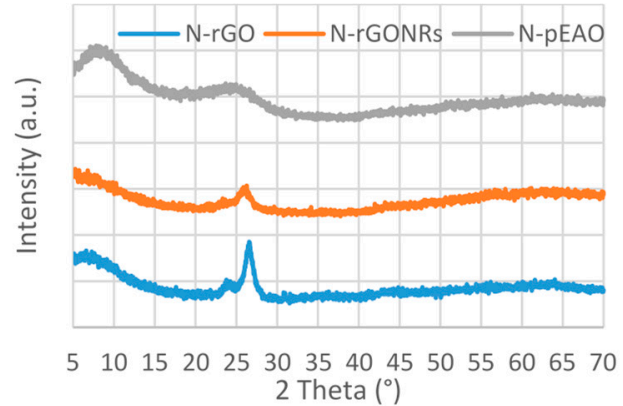

a)

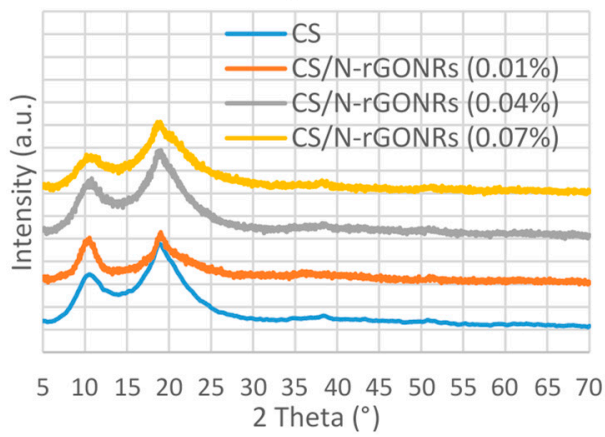

c)

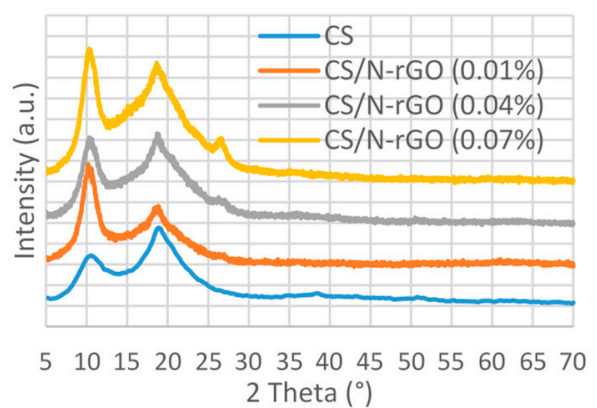

b)

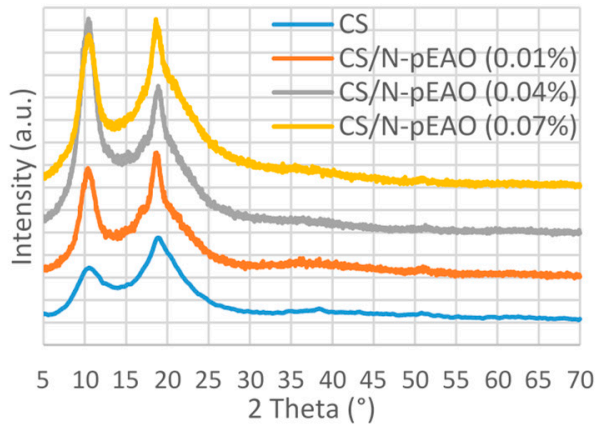

d)

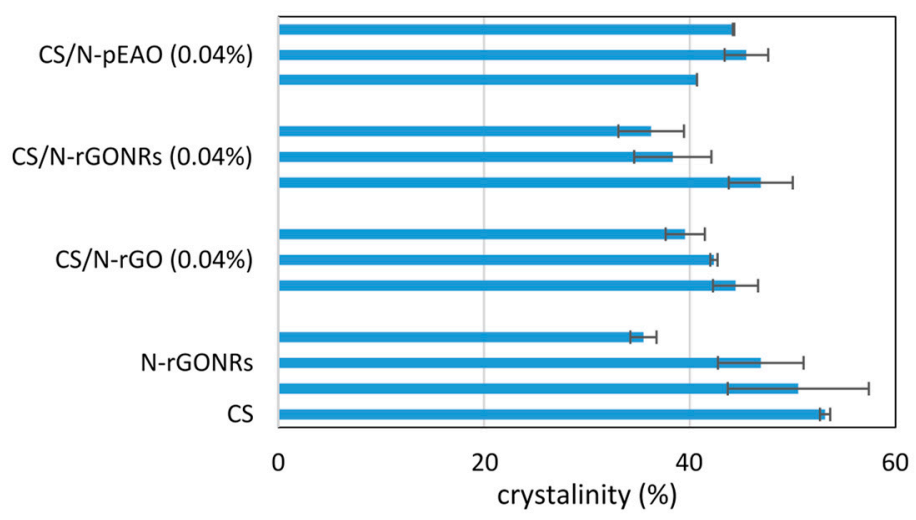

e)

Figure 6. XRD patterns of (a) N-rGO, N-GONRs and N-pEAO and CS/graphene composites, containing $0.01 \%$ to $0.07 \%$ of (b) N-rGO, (c) N-rGONRs, (d) N-pEAO, and (e) calculated crystallinity index $\left(\mathrm{CrI}_{020}=\left(I_{020}-I_{\mathrm{am}}\right) / I_{020} \times 100\right.$ and $\left.\mathrm{CrI}_{110}=\left(I_{110}-I_{\mathrm{am}}\right) / I_{110} \times 100\right)$, where $I_{110}$ represents the maximum absorption intensity during $18-20^{\circ}$, and $I_{110}$ represents $11^{\circ}$ [23]. The CS spectrum was added as control (b-d).

ATR-FTIR analysis aims to identify the potential interactions amongst membrane components, the CS and N-doped graphene components. The vibration spectra of the CS membrane (Figure 7, top-most spectral line on each graph) evidenced typical CS polymer bands, assigned to $\mathrm{O}-\mathrm{H}$ and $\mathrm{NH}_{2}$ vibrations $\left(3700-3000 \mathrm{~cm}^{-1}\right), \mathrm{C}-\mathrm{H}$ stretching vibration (3000-2800 $\left.\mathrm{cm}^{-1}\right), \mathrm{C}=\mathrm{O}$ stretching, $\mathrm{N}-\mathrm{H}$ bending vibrations within the residual amide $\mathrm{N}$-acetyl $\left(\mathrm{NHCOCH}_{3}\right)$ group and $\mathrm{CH}_{2}$ bending vibration in the $\mathrm{CH}_{2} \mathrm{OH}$ group $\left(1647 \mathrm{~cm}^{-1}, 1583.7 \mathrm{~cm}^{-1}\right.$ and $1421 \mathrm{~cm}^{-1}$, respectively), C-OH stretching of the primary alcohol group $\left(1378 \mathrm{~cm}^{-1}\right)$, symmetric and asymmetric stretch of a C-O-C glucoside bridge 
( $1151 \mathrm{~cm}^{-1}$ and $\sim 1061 \mathrm{~cm}^{-1}$, respectively) and C-O vibration of a secondary OH group $\left(\sim 1028 \mathrm{~cm}^{-1}\right)$ [25].
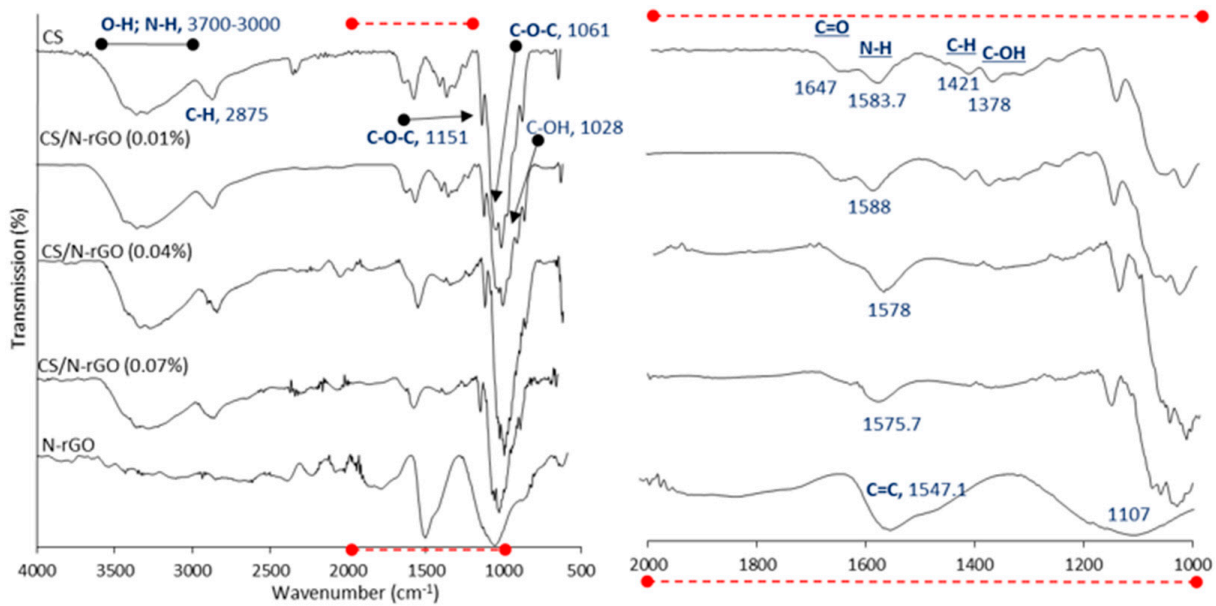

a)
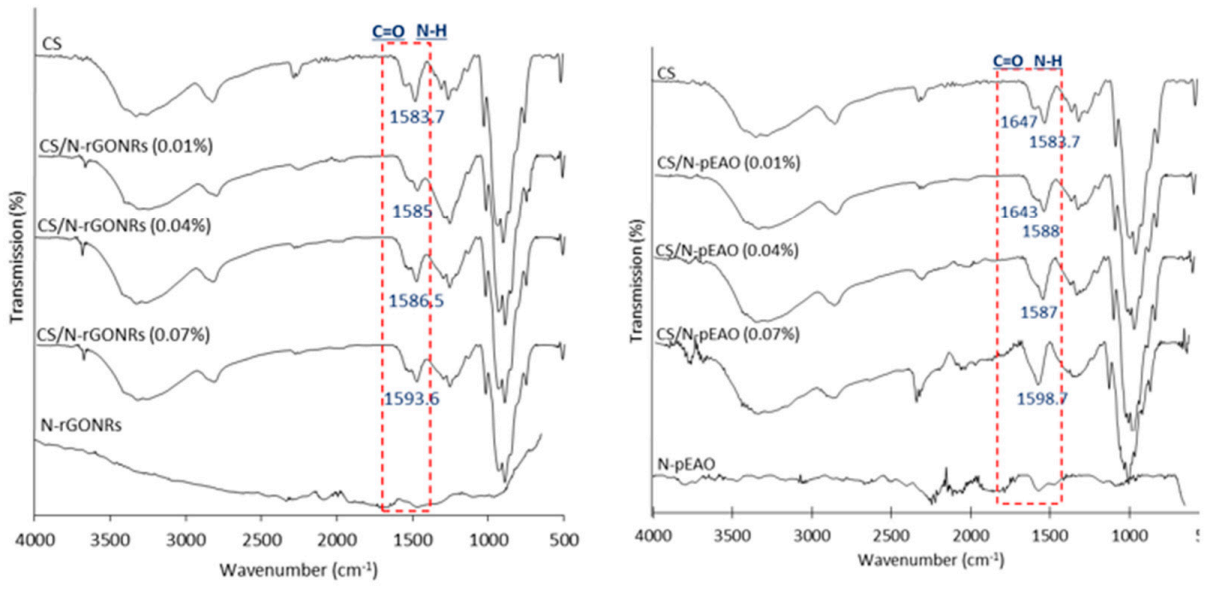

b)

c)

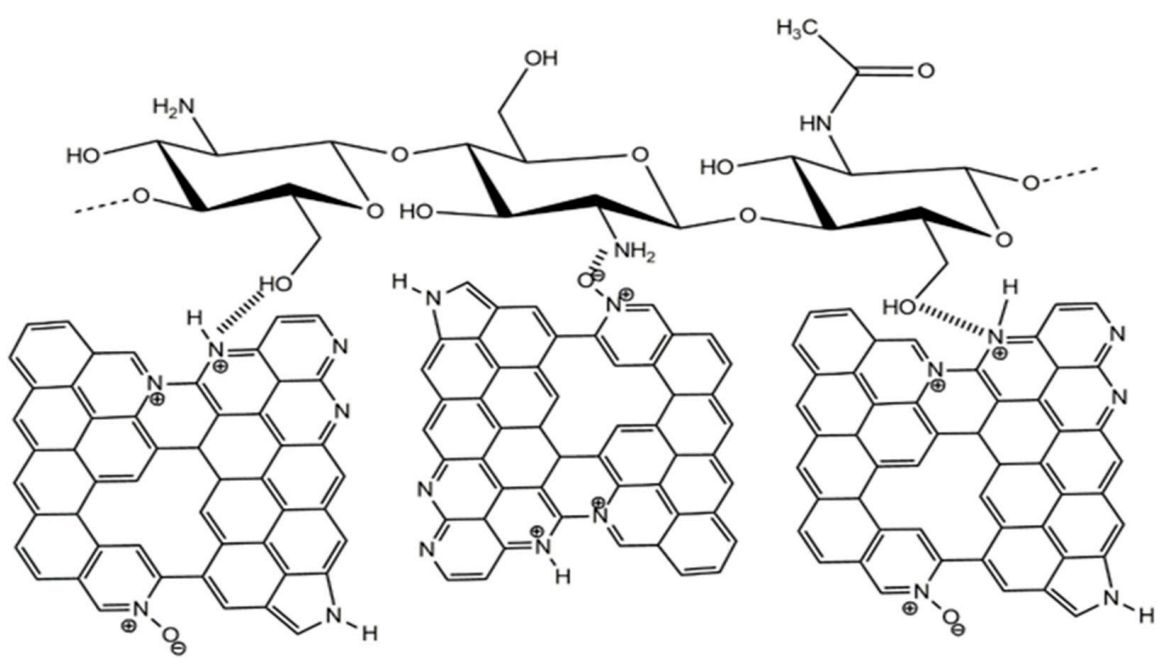

d)

Figure 7. FTIR spectrum of neat CS and CS/graphene composite membranes, containing $0.01 \%$, $0.04 \%$ and $0.07 \%$ of (a) N-rGO, (b) N-rGONRs and (c) N-pEAO. The spectra are offset vertically to aid visibility. (d) Tentative scheme of CS-graphene interaction within composite membranes. 
Figure 7 demonstrates the FTIR spectrum of the CS composite membranes, containing different concentrations of graphene-based particles N-rGO (a), N-rGONRs (b), and NpEAO (c), where the spectrum (a) on the right is the detailed figure which focused on the spectral range of interest $\left(\sim 1600 \mathrm{~cm}^{-1}\right.$ to $1400 \mathrm{~cm}^{-1}$, covering the $\mathrm{N}-\mathrm{H}$ and $\mathrm{C}=\mathrm{O}$ vibration regions), which is most affected by components' mixing. The absorption band at $1647 \mathrm{~cm}^{-1}$ is characteristic of the $\mathrm{C}=\mathrm{O}$ stretching mode of the amide group, while $1583.7 \mathrm{~cm}^{-1}$ is related to the bending mode of the $\mathrm{N}-\mathrm{H}$ in the primary amine. The position of both is affected by addition of $\mathrm{N}$-doped graphene particles within the CS polymer matrix, as observable vibration shifts (respective to the CS band position, as control) are present: the $\mathrm{N}-\mathrm{H}$ vibration band shifts from $1583.7 \mathrm{~cm}^{-1}$ (in CS) to higher wavenumbers, i.e., $1588 \mathrm{~cm}^{-1}$, $1585 \mathrm{~cm}^{-1}$ and $1588 \mathrm{~cm}^{-1}$ in CS/N-rGO, CS/N-rGONRs, and CS/N-pEAO, respectively, in the case of the lowest $(0.01 \%)$ loading. Increasing the loading percentage (up to $0.07 \%$ ), further shifted the vibration to higher $1593.6 \mathrm{~cm}^{-1}$ and $1598.7 \mathrm{~cm}^{-1}$ in CS/N-rGONRs and CS/N-pEAO, respectively, while opposite shifting (to $1575.7 \mathrm{~cm}^{-1}$ ) was observed in the case of $\mathrm{CS} / \mathrm{N}-\mathrm{rGO}$, the latter due to interference with the $\mathrm{C}=\mathrm{C}$ related band at $1547 \mathrm{~cm}^{-1}$. These shifts indicate hydrogen bonding between CS amines and the rGO (remaining) oxide groups (tentative scheme in Figure 7d), which were also detected by XPS. To this end, the covalent bonding between both components, as described in the literature for a similar $\mathrm{CS} / \mathrm{rGO}$ system [26], can hardly be speculated here, as no increase in intensity of vibration at $1647 \mathrm{~cm}^{-1}$ (C=O band), relative to the intensity of band related to $\mathrm{N}-\mathrm{H}\left(1583.7 \mathrm{~cm}^{-1}\right)$ can be detected as confirmation of new amide bonds among the residual oxygen groups of $\mathrm{N}$-doped graphene components and CS amines [27]. To sum up, shortly, the largest change was observed within the CS/N-pEAO composite membranes, where significant reduction in intensity down to complete disappearance was observed for the $1647 \mathrm{~cm}^{-1}$ band, with concentration increase of the N-pEAO component, which aligns with the XRD findings of the largest crystallinity, potentially due to the largest interfacial contact and bonding between both components. Importantly, the polyenaminone oxygen functional groups, remaining also in the $\mathrm{N}-\mathrm{pEAO}$ product $(9.79 \%$ of $\mathrm{N}-\mathrm{O}$ groups were detected by the XPS survey and $\mathrm{CHN}$ elemental analysis, Figure 2c), and the same can form hydrogen bonds with the CS-related $\mathrm{NH}_{2}$ or $\mathrm{NHCOCH}_{3}$ group, which can be responsible for the described larger changes in the amide region for this sample.

\subsection{Mechanical Properties}

As mentioned in the beginning, the rationality behind the addition of N-rGO, NrGONRs, and N-pEAO to the CS matrix is not only to enhance the ionic conductivity, but also to reinforce the relatively weak CS membrane mechanically.

Results obtained by the tensile test (Figure 8) demonstrate that the neat CS membrane has a tensile modulus of $42.26 \pm 13.5 \mathrm{MPa}$, tensile strength of $4.52 \pm 3.1 \mathrm{MPa}$ and elastic elongation of $24.73 \pm 1.8 \%$. Separate addition of low concentration $(0.01 \%) \mathrm{N}-\mathrm{rGO}$ and $\mathrm{N}$-pEAO improved the tensile modulus (506.8\% and $312.7 \%$, respectively) and tensile strength $(392.5 \%$ and $220.9 \%$, respectively) significantly, which can be attributed to their structural features (2D and 3D, versus 1D shape) and orientation within the CS matrix, rather than superior dispersibility over the N-rGONRs, as the same $\zeta$ potential (Figure 1 ) of $\sim 10 \mathrm{mV}$ was measured at $\mathrm{pH} 6$ for all types. We assume that the in-plane direction of performing the tensile strength affects the results in the way that a sheet-like orientation of the filler (as typical for flake-like rGO) is most beneficial. Reduction of tensile modulus and tensile strength in the case of N-rGONRs' addition can be attributed to the disturbance of the interaction between CS polymers upon the addition of this component [12], already at low concentration, where even the largest surface area of $200.3 \mathrm{~m}^{2} / \mathrm{g}$ (BET data) compared to other fillers cannot compensate. Addition of higher concentrations of each type of filler reduce the tensile modulus and tensile strength values, which are expected and reported phenomena when graphene-derivatives are dispersed within the CS films, instead of reduction after membranes' formation; in the latter, the short-range interactions are more intensive, due to the proximity of both components [28]. Previous studies [29] utilizing CS 
and GO as membrane components explained that, at low content, GO can be dispersed in the polymer solution uniformly and had good adhesion with the polymer matrix, while, with the further increase of the GO content, the GO dispersion in the polymer solution deteriorated, resulting in poorer adhesion with the polymer and, thus, decreased the mechanical property of the membrane. The strengthening effects of GO on polymers is related mainly to the properties of GO nanolayers, the dispersion state of GO in the polymer, the interphase interactions, as well as changes in the crystalline structures of semi-crystalline polymers. As is obvious, the lower contents, e.g., $0.01 \%$, lead to better dispersion and, therefore, more efficient reinforcement.

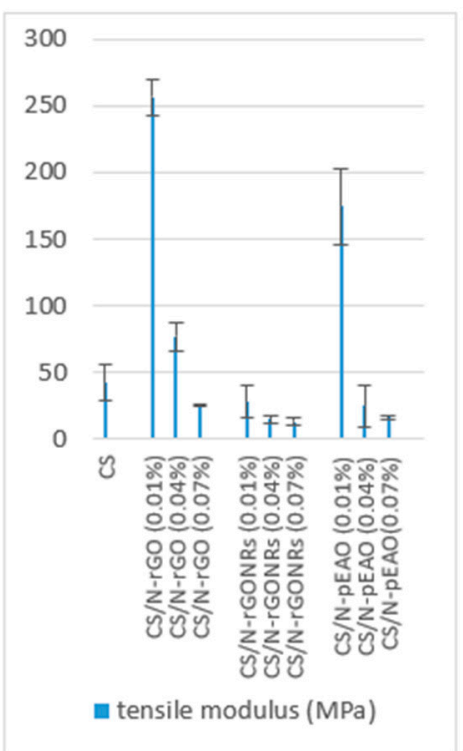

a)

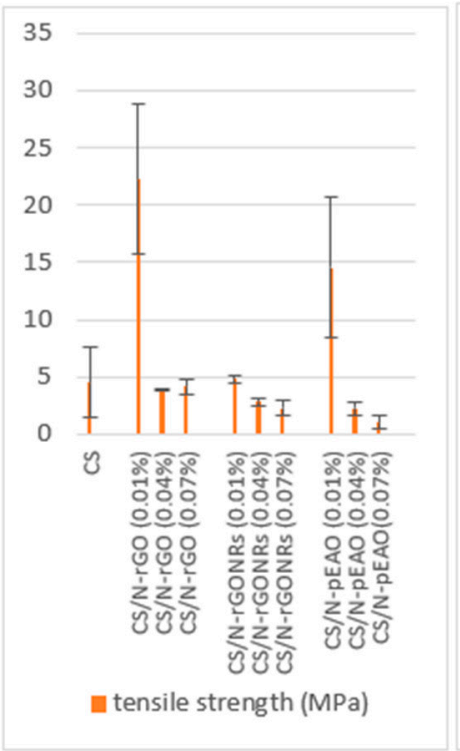

b)

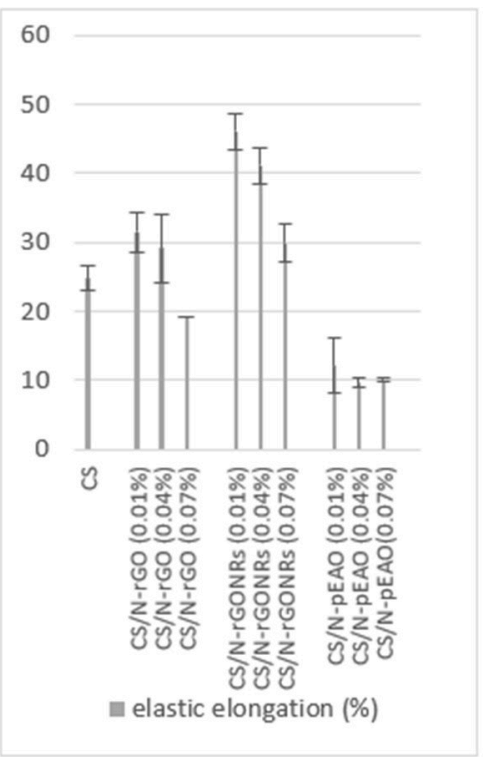

c)

Figure 8. (a) Tensile modulus (MPa), (b) Tensile strength (MPa) and (c) Elastic elongation (\%) data obtained at tensile testing of neat CS and CS/graphene composite membranes, containing $0.01 \%, 0.04 \%$, and $0.07 \%$ of N-rGO, N-rGONRs and N-pEAO.

High magnification SEM images reveal continuous, film-like features in the case of the CS membrane with $0.01 \% \mathrm{~N}-\mathrm{rGO}$ and $\mathrm{N}-\mathrm{pEAO}$, while discontinuous, the cracked surface was seen in case of N-rGONRs, which we anticipate having a negative effect on mechanical properties. On the contrary, the elastic elongation was highest for N-rGONRs containing CS membranes and lowest for N-pEAO containing CS membranes at respective concentrations, which implied elasticity introduced by the ribbons-shaped rGO, while sheet-like N-rGO and porous N-pEAO were relatively more rigid within the (in-plane) direction, which was adapted during the tensile test.

\subsection{KOH Uptake, in Plane Swelling and Ethanol Permeability}

For a given $\mathrm{AEM}$, the $\mathrm{KOH}$ uptake of the polymeric membrane is a critical parameter, because if it goes too high it may lead to cathode flooding, whereas going too low may result in poor transport properties, lowering the cell performance. Moreover, the $\mathrm{KOH}$ uptake has a significant effect on $\mathrm{OH}$ - ion conductivity and the overall properties of the membrane, especially in the case of highly hydrophilic polymers, such as CS.

Figure 9 demonstrates the (a) $\mathrm{KOH}$ uptake and (b) Swelling ratio of $1 \% \mathrm{CS}$ membranes with the addition of a N-rGO, N-rGONRs and N-pEAO at three different concentrations $(0.01 \%, 0.04 \%$, and $0.07 \%)$. 


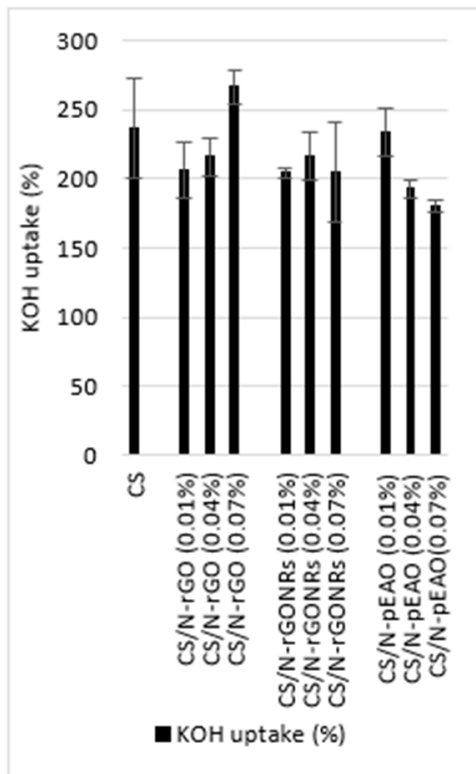

a)

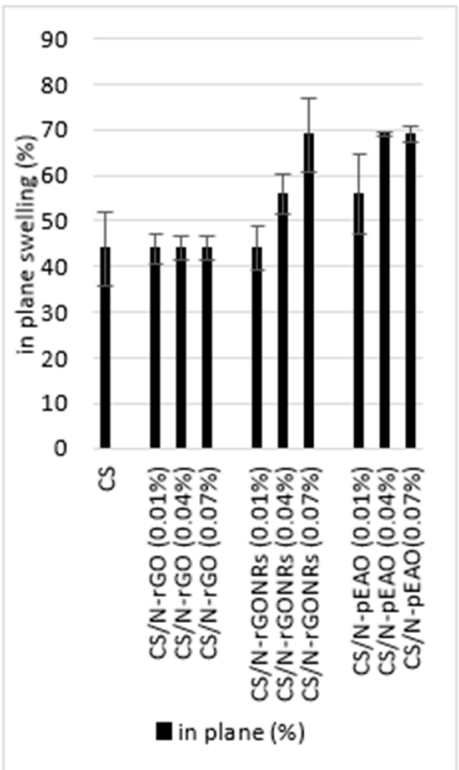

b)

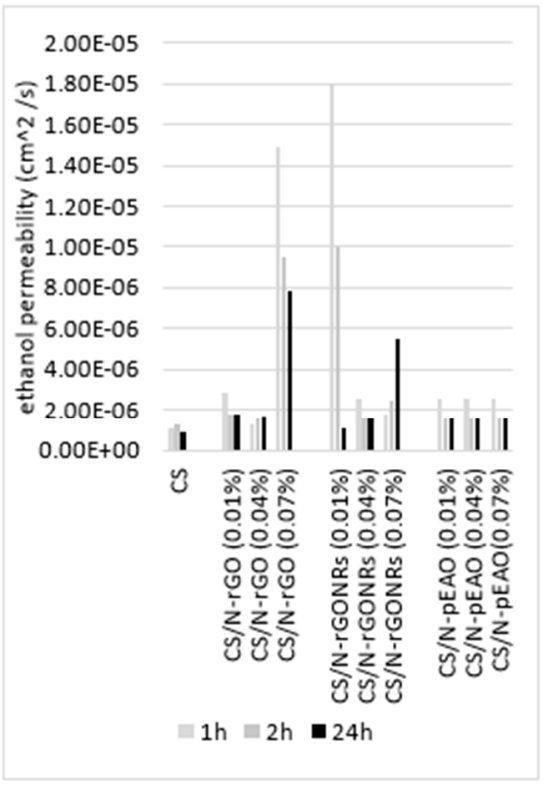

c)

Figure 9. (a) $\mathrm{KOH}$ uptake (\%) and (b) in-plane swelling (\%) data, obtained after $24 \mathrm{~h}$ immersion in $6 \mathrm{M} \mathrm{KOH}$, and (c) ethanol permeability $\left(\mathrm{cm}^{2} / \mathrm{s}\right)$, obtained after $1 \mathrm{~h}, 2 \mathrm{~h}$, and $24 \mathrm{~h}$ measurement within a constructed cell of neat CS and CS/graphene composite membranes, containing $0.01 \%, 0.04 \%$, and $0.07 \%$ of N-rGO, N-rGONRs and N-pEAO, all estimated as a working temperature of $25^{\circ} \mathrm{C}$.

A neat CS membrane has a relatively low $\mathrm{KOH}$ uptake of $236 \pm 35.7 \%$, compared to CS swelling in water, due mainly to deionization at such high $\mathrm{pH}$ [30], which is expected for a non-crosslinked membrane made from highly hydrophilic biopolymer. The $\mathrm{KOH}$ uptake was reduced by $18.2 \%$ and $23.5 \%$ after loading with $0.04 \%$ and $0.07 \% \mathrm{~N}-\mathrm{pEAO}$, respectively (Figure 9a). These membranes demonstrate the most pronounced interactions between the components (as seen by FTIR), and high magnification SEM visualized an integrated system, which influenced the mechanical properties positively, and restricted large $\mathrm{KOH}$ uptake. The same membranes demonstrated filler concentration-dependent in-plane swelling, which may be a consequence of the adaption of CS molecules around/within the 3D porous $\mathrm{N}$-pEAO particles, and we speculated that a non-restricted chain relaxation occurred due to molecular sorption in $6 \mathrm{M} \mathrm{KOH}$. In the case of CS loading with the largest $(0.07 \%)$ concentration of $\mathrm{N}-\mathrm{rGO}$, the $\mathrm{KOH}$ uptake increased by $12.8 \%$, which was the largest increase among all membranes containing filler. The same sample demonstrated visible phase separation between CS and N-rGO on the high magnification SEM, and will be described in the next paragraph as the membrane with the highest ethanol permeability. Nevertheless, the same sample did not evidence the larger in- plane swelling compared to other concentrations of the same filler, which implied possible through plane swelling due to the specific orientation of CS/N-rGO within the membrane, where a not well-adhered interphase allows larger $\mathrm{KOH}$ intake. Swelling to a certain extent is useful, as the membrane maintained better contact with the gas diffusion electrode and minimized the interfacial resistance of the cells during hydration/dehydration cycles [31].

Fuel permeability is one of the key parameters that must be considered in evaluation of membrane performance. In the case of ethanol permeability through the membrane, a reduction occurs in the electrolytic activity of cathode-catalytic catalysis, density, and fuel consumption in fuel cells. Ethanol mixes instantly with water, and, thus, penetrates the $\mathrm{OH}$ - conducting membrane easily, where it can combine and react with the migrated electrocatalysts to accelerate the degradation process. On another hand, ethanol can pass through the membrane, entering the cathode and interfering with the cathode reaction, in addition to electrocatalyst poisoning. 
Ethanol permeability measurement was carried out through an ex-situ test, using the diffusion model. A cell consists of two glass reservoirs: reservoir A filled with $25 \mathrm{~mL}$ of $6 \mathrm{M} \mathrm{KOH}$ and reservoir B filled with $25 \mathrm{~mL}$ of $2 \mathrm{M} \mathrm{EtOH} / 6 \mathrm{M} \mathrm{KOH}$. The membrane, with an area of $66.04 \mathrm{~cm}^{2}$, is located between the two temperature-controlled (thermostated at $25{ }^{\circ} \mathrm{C}$ ) diffusion cells. The ethanol concentration was determined indirectly, using calibration curve plotting conductivity of different $\mathrm{EtOH} / 6 \mathrm{M} \mathrm{KOH}$ mixtures. According to the results in Figure 9c, the lowest ethanol permeability after $1 \mathrm{~h}$ exposure in the cell was measured for neat CS (reference), and was $9.25 \times 10^{-7} \mathrm{~cm}^{2} / \mathrm{s}$, which is comparable to the literature reports using crosslinked CS under higher temperature $\left(40^{\circ} \mathrm{C}\right)$ [32]. The permeability was found to increase after the addition of filler in all three cases, and the most pronounced (close to 10-fold) increase was observed in CS/N-rGO (0.07\%) and CS/N-rGONRs $(0.01 \%)$ membranes. We anticipate that the presence of fillers, especially in cases when low interfacial adhesion between components is present, induces formation of intermediate spaces, which do not restrict the migration of ethanol molecules. In the case of CS/N-rGONRs $(0.01 \%)$, such voids were even visible on a large-scale, appearing as surface cracks on high magnification SEM micrographs. A less affected composite membrane, with the lowest increase of ethanol permeability relative to neat CS, was observed in membranes containing N-pEAO, which we assumed to be a consequence of the 3D porosity of the filler material, allowing inclusion of CS molecules, close packing, and the already described molecular (H-bonding) interactions. This, in turn, reduced the permeability; the same filler demonstrated a reinforcing effect, also improving the mechanical properties. The relation of mechanical properties and ethanol permeability also aligned well in the case of the sample with the highest permeability, i.e., CS/N-rGONRs $(0.01 \%)$, the same having the lowest tensile strength and modulus, which was attributed to its (1D) structural organization. This membrane was also the only sample where increase of filler concentration reduced the permeability, which was not seen in N-pEAO and N-rGO, the latter even increasing the permeability. Such random behavior can only be explained by the function of the filler shape and its orientation, guiding the structuring of the composite membrane as whole.

At $24 \mathrm{~h}$ measurement, clear relations among composites were observed, in terms of ethanol permeability, where increasing of filler concentration (from $0.01 \%$ to $0.07 \%$ ) increased the permeability, excluding the membrane containing N-pEAO, where similar values were obtained for all concentrations. Moreover, in almost all cases, permeability was reduced with time, which may be related to swelling of the membrane and/or migration of fillers, which can only be speculation at this point. We expect that, at one follow up study, the introduction of a zero or short length crosslinker, can evoke closer packaging, and improve the ethanol permeability profile, simultaneously improving the mechanical profile as well.

\subsection{Performance of CS-Based Membranes within a Single Cell Test}

The membrane performance in fuel cells is determined in direct alkaline ethanol test cells. The effect of different N-doped graphene-based components and their loading concentrations was investigated, as well as the influence of temperature and fuel concentration on the DAEFC membrane performance. Figure 10 shows typical DAEFC I V (left axis) and I-P (right axis) plots of the pristine CS membrane, as well as of the as prepared CS/NrGO, CS/N-rGONRs, and CS/N pEAO membranes. The cell voltage and the maximum power density of all samples increased with ascending temperatures, independent of the fuel concentration (Figure S4, Table 1$)$. CS/N-rGONRs (0.07\%) shows as an example an increase in open circuit voltage (OCV) from 737 to $895 \mathrm{mV}$, and maximum power densities of 3.6-10 $\mathrm{mWcm}^{-2}$ at a fuel mixture of $1 \mathrm{M} \mathrm{EtOH}$ and $1 \mathrm{M} \mathrm{KOH}$ when the cell temperature was raised from ambient temperature to $57^{\circ} \mathrm{C}$. In a fuel solution of $3 \mathrm{M} \mathrm{EtOH} / 5 \mathrm{M} \mathrm{KOH}$ at $57^{\circ} \mathrm{C}$, the $\mathrm{OCV}$ was approx. $150 \mathrm{mV}$ and $\mathrm{P}_{\max }$. approx. $13 \mathrm{mWcm}^{-2}$ higher than at ambient temperature. This is consistent with similar studies [31] and is attributed to the improved reaction kinetics at the electrodes and conductivity of the cell at higher temperatures. 

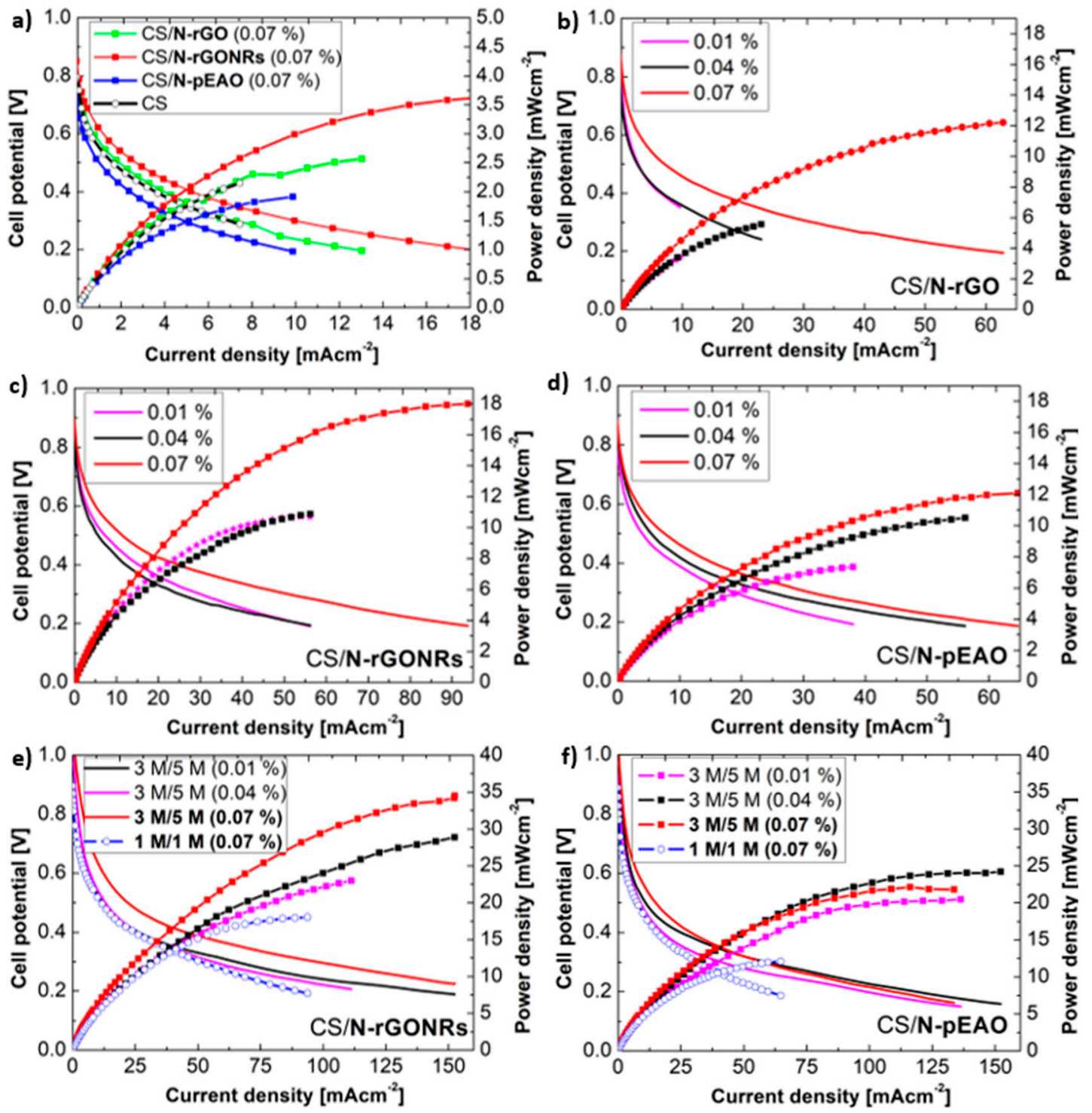

Figure 10. Typical Direct Ethanol Alkaline Fuel Cell (DEAFC) discharged cell voltage and power density of (a) CS membranes at room temperature with $1 \mathrm{M} \mathrm{EtOH} / 1 \mathrm{M} \mathrm{KOH},(\mathbf{b}-\mathbf{d}) \mathrm{CS}$ membranes at $57^{\circ} \mathrm{C}$ and $1 \mathrm{M} \mathrm{EtOH} / 1 \mathrm{M} \mathrm{KOH}$, and (e-f) $\mathrm{CS}$ membranes at $57^{\circ} \mathrm{C}$ and $3 \mathrm{M} \mathrm{EtOH} / 5 \mathrm{M} \mathrm{KOH}$.

Table 1. Open circuit voltage $(\mathrm{OCV})$ and $\mathrm{P}_{\max }$. of $\mathrm{CS} / \mathrm{N}-\mathrm{rGONRs}(0.07 \%)$ as a function of temperature and concentration.

\begin{tabular}{ccccc}
\hline Temperature & $\begin{array}{l}\text { OCV } \\
(\mathbf{m V})\end{array}$ & $\begin{array}{c}\mathbf{P}_{\text {max. }} \\
\left(\mathbf{m W c m} \mathbf{2}^{-2}\right)\end{array}$ & $\begin{array}{l}\text { OCV } \\
(\mathbf{m V})\end{array}$ & $\begin{array}{c}\mathbf{P}_{\text {max. }} \\
\left(\mathbf{m W c m} \mathbf{2}^{-2}\right)\end{array}$ \\
\hline $\mathrm{RT}\left(22^{\circ} \mathrm{C}\right)$ & $1 \mathrm{M} \mathrm{EtOH} / 1 \mathrm{M} \mathrm{KOH}$ & $3 \mathrm{M} \mathrm{EtOH} / 5 \mathrm{M} \mathrm{KOH}$ \\
\hline $35^{\circ} \mathrm{C}$ & 789 & 3.6 & 948 & 11.9 \\
\hline $43^{\circ} \mathrm{C}$ & 815 & 6.7 & 1003 & 20.4 \\
\hline $50^{\circ} \mathrm{C}$ & 848 & 10.1 & 1039 & 26.3 \\
\hline $57^{\circ} \mathrm{C}$ & 869 & 13.8 & 1082 & 33.6 \\
\hline
\end{tabular}

Measurements with higher concentrated fuel were carried out for the CS/N-rGONRs and $\mathrm{CS} / \mathrm{N}$ pEAO to test the influence of $\mathrm{EtOH}$ and $\mathrm{KOH}$ concentration on membrane 
performance in test cells. The cell voltage and the maximum power density increased when a mixture of $3 \mathrm{M} \mathrm{EtOH} / 5 \mathrm{M} \mathrm{KOH}$ was used instead of $1 \mathrm{M} \mathrm{EtOH}$ and $1 \mathrm{M} \mathrm{KOH}$, as can be seen in Figure 10e,f. CS/N-rGONRs $(0.07 \%)$ had a $17 \mathrm{mVcm}^{-2}$ higher $\mathrm{P}_{\max }$. and the OCV was $200 \mathrm{mV}$ higher for the concentrated fuel. OCV and $\mathrm{P}_{\max }$. of CS/N pEAO $(0.07 \%)$ increased from $827 \mathrm{mV}$ and $12 \mathrm{mWcm}^{-2}$ to $1017 \mathrm{mV}$ and $22 \mathrm{mWcm}^{-2}$. The higher cell performance, especially in the low current density region, was caused on the one hand by the fact that the ethanol availability was improved, thus ensuring sufficient ethanol adsorption and $\mathrm{OH}^{-}$on the active surface. Therefore, the reaction kinetics in the EOR were enhanced and led to better cell performance. On the other hand, the cell performance was affected by the higher alkaline anode feed concentration. The $\mathrm{OH}^{-}$ion conductivity of the AEM contributes mainly to an increase of cell voltage and power density. In addition, more $\mathrm{OH}^{-}$ions are provided for faster EOR kinetics and mass transport at the anode [33].

The influence of the addition of N-doped graphene-based components to the CS membranes on the Direct Ethanol Alkaline Fuel Cell (DEAFC) performance was examined by comparing CS/N-rGO, CS/N rGONRs and CS/N pEAO with the pristine CS membrane. In Figure 10a, the I-V and I-P plots of the CS membranes containing the highest N-rGO, $\mathrm{N}$-rGONRs and $\mathrm{N}$-pEAO concentration $(0.07 \%)$ are compared with blank CS membrane at room temperature and $1 \mathrm{M} \mathrm{EtOH} / 1 \mathrm{M} \mathrm{KOH}$ anode fuel. CS/N rGONRs $(0.07 \%)$ significantly $\left(\mathrm{P}_{\max .}=3.7 \mathrm{mWcm}^{-2}\right)$ and $\mathrm{CS} / \mathrm{N}-\mathrm{rGO}(0.07 \%)$ slightly $\left(\mathrm{P}_{\max }=2.5 \mathrm{mWcm}^{-2}\right)$ outperformed the performance of the pristine CS membrane $\left(\mathrm{P}_{\max } .=2.2 \mathrm{mWcm}^{-2}\right)$, whereas CS/N pEAO (0.07\%) illustrated lower cell potential and power density values. This shift in power output might be explained by the surface morphology, mechanical properties, and conductivity of the membranes. A smooth surface reduces the interfacial resistance in the membrane electrode assembly [12]. Therefore, pristine CS might show better cell performance at room temperature than $\mathrm{CS} / \mathrm{N}$ pEAO. The smoother surface morphology of CS/N-rGO and CS/N rGONRs compared to CS/N pEAO was compensated by a higher membrane conductivity, resulting in a better performance of the blank CS membrane. In addition, elastic elongation was the highest for $\mathrm{N}$ rGONRs containing CS membranes, and the lowest for N-pEAO, which also influenced the quality of the MEA.

In contrast to lower temperatures, $\mathrm{CS} / \mathrm{N}$ pEAO exceeded the performance of $\mathrm{CS} / \mathrm{N}$ rGO at higher temperatures, whereas CS/N rGONRs still showed the highest values (Figure 10e,f, and Table S1). In a $3 \mathrm{M} \mathrm{EtOH} / 5 \mathrm{M} \mathrm{KOH}$ solution, CS/N rGONRs also showed higher maximum power densities compared to the CS/N pEAO samples. The reason for this might be changes in the quality of the MEA at higher temperatures. In addition, $\mathrm{N}$ rGONRs had the highest specific surface area according to the BET measurements of $200 \mathrm{~m}^{2} / \mathrm{g}$, possessing predominantly pyridinic $\mathrm{N}$ (above 42 at.\%) instead of graphitic $\mathrm{N}$, and presented the highest water uptake from the atmosphere.

The effect of $\mathrm{N}$-doped graphene-based loading concentrations in the $1 \mathrm{M} \mathrm{EtOH} / 1$ $\mathrm{M} \mathrm{KOH}$ anode fuel is illustrated in Figure 10b-d. The cell performance increased for all three samples with ascending $\mathrm{N}$-doped graphene-based loading. CS/N-rGO showed the highest increase of $P_{\max }$. from $3.4 \mathrm{mWcm}^{-2}$ to $12 \mathrm{mWcm}^{-2}$ when the $\mathrm{N}-\mathrm{rGO}$ was raised from $0.01 \%$ to $0.07 \%$. The maximum power density of CS/N rGONRs and CS/N pEAO was $7 \mathrm{mWcm}^{-2}$ and $4.5 \mathrm{mWcm}^{-2}$ higher, respectively. This correlated with the different mechanical properties at a higher N-doped graphene-based loading, lower crystallinity, and a higher swelling ratio. Swelling to a certain extent is useful in improving contact with the gas diffusion electrode and minimizing cell interfacial resistance during hydration/dehydration cycles [31].

In summary, the $\mathrm{CS} / \mathrm{N}$ rGONRs with the highest $\mathrm{N}$-doped graphene-based loading $(0.07 \%)$ at a temperature of $57{ }^{\circ} \mathrm{C}$ and the concentrated $3 \mathrm{M} \mathrm{EtOH} / 5 \mathrm{M} \mathrm{KOH}$ anode fuel presented the best overall performance. The OCV of $1095 \mathrm{mV}$ was close to the theoretical voltage of $1140 \mathrm{mV}$, and a $P_{\max }$. of $34.5 \mathrm{mWcm}^{-2}$ could be achieved at a current density of $152.54 \mathrm{mAcm}^{-2}$. In previous studies [19], the highest reported power density value for CS-based membranes was $62.2 \mathrm{mWcm}^{-2}$ (current density $174 \mathrm{mAcm}^{-2}$ ) at $60{ }^{\circ} \mathrm{C}$ and $72.7 \mathrm{mWcm}^{-2}$ (current density $209 \mathrm{mAcm}^{-2}$ ) at $80{ }^{\circ} \mathrm{C}$. Compared to these 
investigations, lower temperatures $\left(57^{\circ} \mathrm{C}\right.$ instead of $60{ }^{\circ} \mathrm{C}$ and $\left.80^{\circ} \mathrm{C}\right)$, a lower oxygen fuel rate $\left(25 \mathrm{mLmin}^{-1}\right.$ instead of $\left.100 \mathrm{mLmin}^{-1}\right)$ and lower metal loading for the anode $\left(0.75 \mathrm{mgcm}^{-2}\right.$ instead of $\left.2 \mathrm{mgcm}^{-2}\right)$ and for the cathode $\left(0.5 \mathrm{mgcm}^{-2}\right.$ instead of $\left.1 \mathrm{mgcm}^{-2}\right)$ were used. Despite these changes or reductions, excellent results were achieved.

\section{Conclusions}

Use of anion exchange membranes as ion-conducting polyelectrolytes within fuel cells is a promising, cost-effective approach, where research is focused on their stability, permeability, conductivity, and ultimate cell performance. We have shown that $\mathrm{N}$-doped graphene derivatives (N-rGO, N-rGONRs, and N-pEAO) play an important role in CSbased nanocomposite membranes, which are relevant for direct alkaline ethanol fuel cells. In particular, N-doped graphene derivatives in concentrations between $0.01 \mathrm{wt} . \%$ and $0.07 \mathrm{wt} . \%$ change the morphology of the CS membrane drastically due to interactions between the functional groups of CS and N-doped graphene derivatives, as well as (1D, 2D, and 3D) shape of latter. In addition, properties, such as crystallinity, tensile modulus, tensile strength, $\mathrm{KOH}$ uptake, and ethanol permeability within composite membranes were also changed compared to pure CS membranes. The synergistic contribution of graphene derivatives and CS in membranes were tested finally in direct alkaline ethanol test cells. We demonstrated that nanocomposite membranes containing N-rGONRs exceeded the fuel cell performance of the pristine CS membrane significantly. Encouraging fuel cell results point to new sustainable, bio-based membranes for use in alternative energy conversion device applications.

Supplementary Materials: The following are available online at https://www.mdpi.com/1422-0 067/22/4/1740/s1. Figure S1. SEM image of Polyenaminone 4ca [13]. Figure S2. Raman spectra of (a) N-rGO, (b) N-rGONRs, and (c) N-pEAO. Figure S3. CHN elemental analysis of N-rGO, NrGONRs, and N-pEAO. Figure S4. Typical DEAFC discharged cell voltage and power density of CS/N-rGONRs $(0.07 \%$ ) as a function of temperature in (a) $1 \mathrm{M} \mathrm{EtOH} / 1 \mathrm{M} \mathrm{KOH}$ and (b) $3 \mathrm{M} \mathrm{EtOH} / 5 \mathrm{M}$ $\mathrm{KOH}$. Table S1. Pmax. and related current density of CS membranes at $57^{\circ} \mathrm{C}$.

Author Contributions: S.G., M.B., V.H., S.W., and B.G. designed the experiments; S.G., A.O., S.H., M.B., J.S., S.W., and V.H. carried out the experiments. S.G., S.H., S.W., V.H. and B.G. discussed the results and co-wrote the paper. All authors have read and agreed to the published version of the manuscript.

Funding: This research was funded by the Slovenian Research Agency (ARRS), Grant Number: N2-0087, P2-0118, and P1-0175, and the Austrian Science Fund (FWF); Grant Number: I 3871 International projects.

Institutional Review Board Statement: Not applicable.

Informed Consent Statement: Not applicable.

Data Availability Statement: The data presented in this study are available on request from the corresponding author. The data are not publicly available due to privacy reasons.

Acknowledgments: We thank Domen Oštir (University of Ljubljana) for preparing some of the graphenebased materials used in the present study, and Justin Connell (Argonne National Laboratory) for XPS measurements. We also thank Michaela Roschger (TUG) for help in single cell test measurements.

Conflicts of Interest: The authors declare no conflict of interest.

\section{References}

1. Dekel, D.R. Review of cell performance in anion exchange membrane fuel cells. J. Power Sources 2018, 375, 158-169. [CrossRef]

2. Lin, J.-S.; Kumar, S.R.; Ma, W.-T.; Shih, C.-M.; Teng, L.-W.; Yang, C.-C.; Lue, S.J. Gradiently distributed iron oxide@graphene oxide nanofillers in quaternized polyvinyl alcohol composite to enhance alkaline fuel cell power density. J. Membr. Sci. 2017, 543, 28-39. [CrossRef]

3. Chu, J.Y.; Lee, K.H.; Kim, A.R.; Yoo, D.J. Graphene-mediated organic-inorganic composites with improved hydroxide conductivity and outstanding alkaline stability for anion exchange membranes. Compos. Part B Eng. 2019, 164, 324-332. [CrossRef]

4. Abuin, G.C.; Franceschini, E.A.; Nonjola, P.; Mathe, M.K.; Modibedi, M.; Corti, H.R. A high selectivity quaternized polysulfone membrane for alkaline direct methanol fuel cells. J. Power Sources 2015, 279, 450-459. [CrossRef] 
5. Srinophakun, P.; Thanapimmetha, A.; Plangsri, S.; Vetchayakunchai, S.; Saisriyoot, M. Application of modified chitosan membrane for microbial fuel cell: Roles of proton carrier site and positive charge. J. Clean. Prod. 2017, 142, 1274-1282. [CrossRef]

6. Ma, J.; Sahai, Y. Chitosan biopolymer for fuel cell applications. Carbohydr. Polym. 2013, 92, 955-975. [CrossRef] [PubMed]

7. Khan, A.; Goepel, M.; Colmenares, J.C.; Gläser, R. Chitosan-Based N-Doped Carbon Materials for Electrocatalytic and Photocatalytic Applications. ACS Sustain. Chem. Eng. 2020, 8, 4708-4727. [CrossRef]

8. Vaghari, H.; Jafarizadeh-Malmiri, H.; Berenjian, A.; Anarjan, N. Recent advances in application of chitosan in fuel cells. Sustain. Chem. Process. 2013, 1, 16. [CrossRef]

9. Wan, Y.; Peppley, B.; Creber, K.A.; Bui, V.T.; Halliop, E. Quaternized-chitosan membranes for possible applications in alkaline fuel cells. J. Power Sources 2008, 185, 183-187. [CrossRef]

10. Abolhassani, M.; Griggs, C.S.; Gurtowski, L.A.; Mattei-Sosa, J.A.; Nevins, M.; Medina, V.F.; Morgan, T.A.; Greenlee, L.F. Scalable Chitosan-Graphene Oxide Membranes: The Effect of GO Size on Properties and Cross-Flow Filtration Performance. ACS Omega 2017, 2, 8751-8759. [CrossRef]

11. Zhuo, Y.Z.; Lai, A.L.; Zhang, Q.G.; Zhu, A.M.; Ye, M.L.; Liu, Q.L. Enhancement of hydroxide conductivity by grafting flexible pendant imidazolium groups into poly(arylene ether sulfone) as anion exchange membranes. J. Mater. Chem. A 2015, 3, 18105-18114. [CrossRef]

12. Kaker, B.; Hribernik, S.; Mohan, T.; Kargl, R.; Kleinschek, K.S.; Pavlica, E.; Kreta, A.; Bratina, G.; Lue, S.J.; Božič, M. Novel Chitosan- $\mathrm{Mg}(\mathrm{OH}) 2-$ Based Nanocomposite Membranes for Direct Alkaline Ethanol Fuel Cells. ACS Sustain. Chem. Eng. 2019, 7, 19356-19368. [CrossRef]

13. Marcano, D.C.; Kosynkin, D.V.; Berlin, J.M.; Sinitskii, A.; Sun, Z.; Slesarev, A.S.; Alemany, L.B.; Lu, W.; Tour, J.M. Correction to: Improved Synthesis of Graphene Oxide. ACS Nano 2010, 4, 4806-4814. doi:10.1021/nn1006368. ACS Nano 2018, $12,2078$. [CrossRef]

14. Zupanc, A.; Kotnik, T.; Štanfel, U.; Žugelj, H.B.; Kristl, A.; Ručigaj, A.; Matoh, L.; Pahovnik, D.; Grošelj, U.; Opatz, T.; et al. Chemical recycling of polyenaminones by transamination reaction via amino-enaminone polymerisation/depolymerisation. Eur. Polym. J. 2019, 121, 109282. [CrossRef]

15. Abdou, E.S.; Nagy, K.S.; Elsabee, M.Z. Extraction and characterization of chitin and chitosan from local sources. Bioresour. Technol. 2008, 99, 1359-1367. [CrossRef]

16. Cermenek, B.; Genorio, B.; Winter, T.; Wolf, S.; Connell, J.G.; Roschger, M.; Letofsky-Papst, I.; Kienzl, N.; Bitschnau, B.; Hacker, V. Alkaline Ethanol Oxidation Reaction on Carbon Supported Ternary PdNiBi Nanocatalyst using Modified Instant Reduction Synthesis Method. Electrocatalysis 2020, 11, 203-214. [CrossRef]

17. da Luz, F.S.; Garcia Filho, F.C.; del-Río, M.T.G.; Nascimento, L.F.C.; Pinheiro, W.A.; Monteiro, S.N. Graphene-Incorporated Natural Fiber Polymer Composites: A First Overview. Polymers 2020, 12, 1601. [CrossRef] [PubMed]

18. Tomažin, U.; Alič, B.; Kristl, A.; Ručigaj, A.; Grošelj, U.; Požgan, F.; Krajnc, M.; Štefane, B.; Šebenik, U.; Svete, J. Synthesis of polyenaminones by acid-catalysed amino-enaminone 'click' polymerisation. Eur. Polym. J. 2018, 108, 603-616. [CrossRef]

19. Genorio, B.; Harrison, K.; Connell, J.G.; Dražić, G.; Zavadil, K.R.; Markovic, N.M.; Strmcnik, D. Tuning the Selectivity and Activity of Electrochemical Interfaces with Defective Graphene Oxide and Reduced Graphene Oxide. ACS Appl. Mater. Interfaces 2019, 11, 34517-34525. [CrossRef] [PubMed]

20. Joseph, D.; Tyagi, N.; Ghimire, A.; Geckeler, K.E. A direct route towards preparing pH-sensitive graphene nanosheets with anti-cancer activity. RSC Adv. 2014, 4, 4085-4093. [CrossRef]

21. Romanazzi, G.; Feliziani, E.; Sivakumar, D. Chitosan, a Biopolymer with Triple Action on Postharvest Decay of Fruit and Vegetables: Eliciting, Antimicrobial and Film-Forming Properties. Front. Microbiol. 2018, 9, 2745. [CrossRef]

22. Yasin, G.; Arif, M.; Shakeel, M.; Dun, Y.; Zuo, Y.; Khan, W.Q.; Tang, Y.; Khan, A.; Nadeem, M. Exploring the Nickel-Graphene Nanocomposite Coatings for Superior Corrosion Resistance: Manipulating the Effect of Deposition Current Density on its Morphology, Mechanical Properties, and Erosion-Corrosion Performance. Adv. Eng. Mater. 2018, 20, 1701166. [CrossRef]

23. Hai, T.A.P.; Sugimoto, R. Fluorescence control of chitin and chitosan fabricatedviasurface functionalization using direct oxidative polymerization. RSC Adv. 2018, 8, 7005-7013. [CrossRef]

24. Hwang, K.T.; Kim, J.T.; Jung, S.T.; Cho, G.S.; Park, H.J. Properties of chitosan-based biopolymer films with various degrees of deacetylation and molecular weights. J. Appl. Polym. Sci. 2003, 89, 3476-3484. [CrossRef]

25. Gorgieva, S.; Kokol, V. Preparation, characterization, and in vitro enzymatic degradation of chitosan-gelatine hydrogel scaffolds as potential biomaterials. J. Biomed. Mater. Res. Part A 2012, 100, 1655-1667. [CrossRef] [PubMed]

26. Justin, R.; Chen, B. Strong and conductive chitosan-reduced graphene oxide nanocomposites for transdermal drug delivery. J. Mater. Chem. B 2014, 2, 3759-3770. [CrossRef] [PubMed]

27. Gong, Y.; Yu, Y.; Kang, H.; Chen, X.; Liu, H.; Zhang, Y.; Sun, Y.; Song, H. Synthesis and Characterization of Graphene Oxide/Chitosan Composite Aerogels with High Mechanical Performance. Polymers 2019, 11, 777. [CrossRef]

28. Grande, C.D.; Mangadlao, J.; Fan, J.; De Leon, A.; Delgado-Ospina, J.; Rojas, J.G.; Rodrigues, D.F.; Advincula, R. Chitosan CrossLinked Graphene Oxide Nanocomposite Films with Antimicrobial Activity for Application in Food Industry. Macromol. Symp. 2017, 374, 1600114. [CrossRef]

29. Qian, X.; Li, N.; Wang, Q.; Ji, S. Chitosan/graphene oxide mixed matrix membrane with enhanced water permeability for high-salinity water desalination by pervaporation. Desalination 2018, 438, 83-96. [CrossRef] 
30. Maraschin, T.G.; Correa, R.D.S.; Rodrigues, L.F.; Balzarettid, N.M.; Malmonge, J.A.; Galland, G.B.; Basso, N.R.D.S. Chitosan Nanocomposites with Graphene-Based Filler. Mater. Res. 2019, 22, 20180829. [CrossRef]

31. Liao, G.-M.; Yang, C.-C.; Hu, C.-C.; Pai, Y.-L.; Lue, S.J. Novel quaternized polyvinyl alcohol/quaternized chitosan nano-composite as an effective hydroxide-conducting electrolyte. J. Membr. Sci. 2015, 485, 17-29. [CrossRef]

32. Feketeföldi, B.; Cermenek, B.; Spirk, C.; Schenk, A.; Grimmer, C.; Bodner, M.; Koller, M.; Ribitsch, V.; Hacker, V. Chitosan-Based Anion Exchange Membranes for Direct Ethanol Fuel Cells. J. Membr. Sci. Technol. 2016, 6, 1-9. [CrossRef]

33. Abdullah, S.; Kamarudin, S.; Hasran, U.; Masdar, M.S.; Daud, W. Electrochemical kinetic and mass transfer model for direct ethanol alkaline fuel cell (DEAFC). J. Power Sources 2016, 320, 111-119. [CrossRef] 